\title{
DETERMINAÇÃO E QUANTIFICAÇÃO DE FATORES DE INFLUÊNCIA SOBRE A PRODUTIVIDADE DE "HARVESTERS" NA COLHEITA DE MADEIRA
}

MARCELO BRAMUCCI

Dissertação apresentada à Escola Superior de Agricultura “Luiz de Queiroz”, Universidade de São Paulo, para a obtenção do título de Mestre em Recursos Florestais, Área de Concentração: Recursos Florestais, com opção em Manejo de Florestas de Produção.

PIRACICABA

Estado de São Paulo - Brasil

Novembro - 2001 


\title{
DETERMINAÇÃO E QUANTIFICAÇÃO DE FATORES DE INFLUÊNCIA SOBRE A PRODUTIVIDADE DE "HARVESTERS" NA COLHEITA DE MADEIRA
}

\author{
MARCELO BRAMUCCI \\ Engenheiro Florestal
}

Orientador: Prof. Dr. FERNANDO SEIXAS

\begin{abstract}
Dissertação apresentada à Escola Superior de Agricultura “Luiz de Queiroz", Universidade de São Paulo, para a obtenção do título de Mestre em Recursos Florestais, Área de Concentração: Recursos Florestais, com opção em Manejo de Florestas de Produção.
\end{abstract}

PIRACICABA

Estado de São Paulo - Brasil

Novembro - 2001 
Dados Internacionais de Catalogação na Publicação (CIP) DIVISÃO DE BIBLIOTECA E DOCUMENTAÇÃO - ESALQ/USP

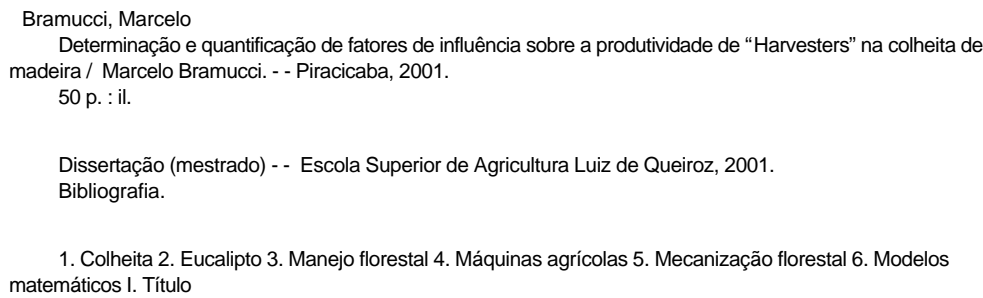

CDD 634.98

\section{"Permitida a cópia total ou parcial deste documento, desde que citada a fonte - $\mathrm{O}$ autor"}



À Fernanda,
a minha grande paixão, DEDICO

Ao FELIPE, que é a razão da minha vida, OFEREÇO 


\section{AGRADECIMENTOS}

Agradeço a todos os que de forma direta ou indireta, colaboraram para a realização deste trabalho.

À Fernandinha, porque sem ela esse trabalho jamais teria sido feito.

À Escrube pelas correções, dicas e risadas na hora do jantar.

Ao Dino e ao Bodo pela força e pelas boas viagens que fizemos.

À todo mundo que ajudou a tomar conta do Felipe.

E ao Felipe, é claro, pelas risadas nas horas de estresse e pela motivação para continuar trabalhando.

Aos amigos, pelo simples fato de vocês existirem.

Ao Prof. Dr. Fernando Seixas, pela orientação e paciência.

Às empresas que colaboraram fornecendo os dados necessários para a realização deste trabalho e aos funcionários dessas empresas que nos ajudaram de forma bastante prestimosa:

Duratex S.A., na pessoa do Sr. José Maria de Sene.

Votorantim Celulose e Papel, nas pessoas dos Srs. Walter Jacob e Ricardo Simonetti Ribeiro

Cia. Suzano de Papel e Celulose, na pessoa do Sr. Jorge Yonezawa Aracruz Celulose nas pessoas dos Srs. Fernando Cabral e Franscisco da Costa Neto

À FAPESP pelo apoio financeiro, sem o qual seria impossível a realização deste. 


\section{SUMÁRIO}

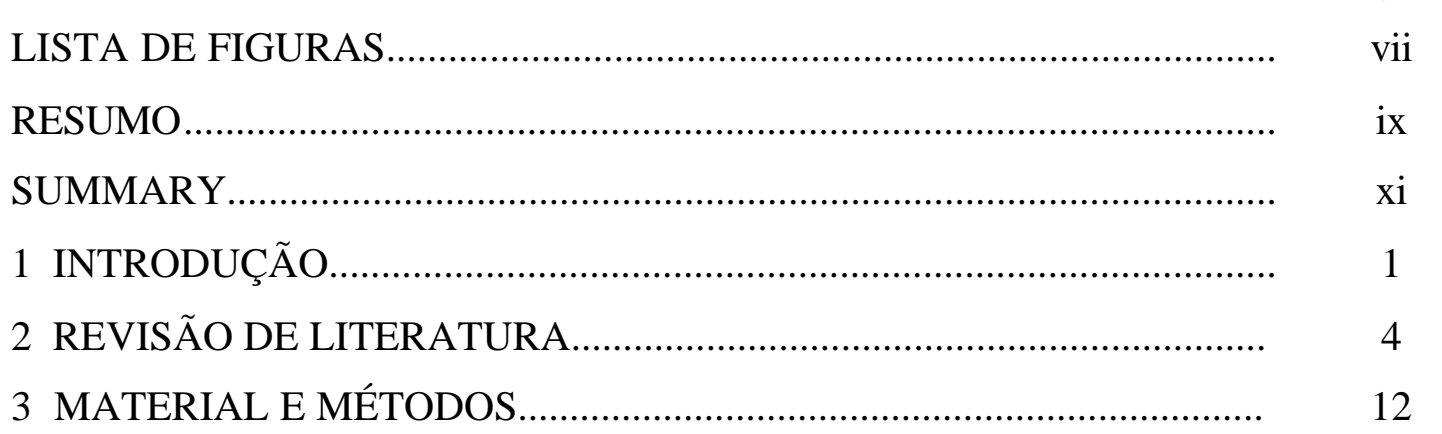

3.1 Levantamento de informações junto às empresas florestais...................... 12

3.1.1 Companhia Suzano de Papel e Celulose............................................... 12

3.1.2 Duratex S.A................................................................................. 13

3.1.3 Votorantim Celulose e Papel................................................................. 16

3.1.4 Aracruz Celulose S.A...................................................................... 17

3.2 Variáveis de influência........................................................................... 19

3.3 Análise estatística................................................................................ 20

4 RESULTADOS E DISCUSSÃO............................................................. 21

4.1 Regressões simples............................................................................. 22

4.1.1 Volume por árvore............................................................................ 22

4.1.2 DAP médio das árvores...................................................................... 24

4.1.3 Altura média das árvores.................................................................... 26

4.1.4 Volume por hectare........................................................................... 27

4.1.5 Árvores por hectare........................................................................... 29

4.1.6 Idade de corte ............................................................................... 30

4.1.7 Experiência do operador.................................................................... 32

4.1.8 Modelos dos equipamentos................................................................... 33 
4.1.9 Combinações máquina/operador....................................................... 36

4.1.10 Pluviosidade no mês da colheita.................................................... 37

4.2 Regressões lineares múltiplas.......................................................... 40

4.2.1 Sistema sem descascamento de madeira feito pelo "harvester"............ $\quad 40$

4.2.2 Sistema com descascamento de madeira feito pelo "harvester" ........... 44

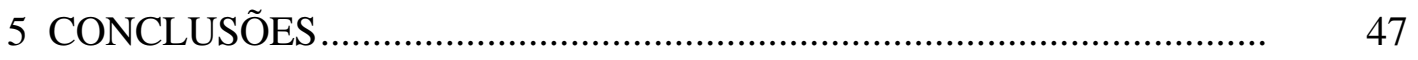

REFERÊNCIAS BIBLIOGRÁFICAS ................................................... 48 


\section{LISTA DE FIGURAS}

Página

1 Harvester "Timberjack 608” de esteiras.......................................... 15

2 Harvester "Valmet 901" 4x4 ................................................... 15

3 Cabeçote processador “Timberjack 762 C”..................................... 17

4 Produtividade dos equipamentos, sem descascamento de madeira, em relação ao volume médio por árvore.................................................. 22

5 Produtividade dos equipamentos, com descascamento de madeira, em relação ao volume médio por árvore................................................... 23

6 Produtividade dos equipamentos, sem descascamento de madeira, em relação ao DAP médio..................................................................... 24

7 Produtividade dos equipamentos, com descascamento de madeira, em relação ao DAP médio.......................................................................... 25

8 Produtividade dos equipamentos, sem descascamento de madeira, em relação à altura média..................................................................... 26

9 Produtividade dos equipamentos, com descascamento de madeira, em relação à altura média....................................................................

10 Produtividade dos equipamentos, sem descascamento de madeira, em relação ao volume hectare............................................................. 28

11 Produtividade dos equipamentos, com descascamento de madeira, em relação ao volume por hectare..........................................................

12 Produtividade dos equipamentos, sem descascamento de madeira, em relação ao número de árvores por hectare ............................................

13 Produtividade dos equipamentos, com descascamento de madeira, em relação ao número de árvores por hectare. 
14 Produtividade dos equipamentos, sem descascamento de madeira, em relação à idade de corte................................................................. 31

15 Produtividade dos equipamentos, com descascamento de madeira, em relação à idade de corte

16 Produtividade dos equipamentos, sem descascamento de madeira, em relação ao tempo de experiência do operador.

17 Produtividade dos equipamentos, sem descascamento de madeira, em relação ao número de combinações máquina/operados........................

18 Produtividade dos equipamentos, com descascamento de madeira, em terreno inclinado, em relação à pluviosidade mensal na ocasião da colheita

19 Produtividade dos equipamentos, com descascamento de madeira, em terreno plano, em relação à pluviosidade mensal na ocasião da colheita

20 Resíduos dos valores previstos pela regressão múltipla para o sistema sem descascamento de madeira.

21 Produtividade de diferentes equipamentos em relação ao volume médio das árvores.

22 Resíduos dos valores previstos pela regressão múltipla para o sistema com descascamento de madeira. 


\title{
DETERMINAÇÃO E QUANTIFICAÇÃO DE FATORES DE INFLUÊNCIA SOBRE A PRODUTIVIDADE DE “HARVESTERS” NA COLHEITA DE MADEIRA
}

\author{
Autor: MARCELO BRAMUCCI \\ Orientador: Prof. Dr. FERNANDO SEIXAS
}

\section{RESUMO}

Somente o setor de papel e celulose brasileiro teve em 2000 um faturamento de US\$ 7,5 bilhões, com o consumo de 14 milhões de $\mathrm{m}^{3}$ de madeira de eucalipto. As operações de colheita e transporte florestal chegam a ser responsáveis por 50\% do custo final da madeira posto fábrica. Em diversos sistemas de colheita mecanizada, o "harvester" é a máquina base utilizada na derrubada de árvores e processamento da madeira. Trata-se de um equipamento de custo elevado e de alta tecnologia, justificandose estudos no sentido de possibilitar um planejamento mais preciso das operações e o melhor aproveitamento dos equipamentos em termos de horas produtivas. $\mathrm{O}$ presente trabalho teve como objetivo, a partir de dados obtidos junto a empresas que utilizam "harvesters" para colheita e processamento de madeira de eucalipto, analisar a forma de influência das diferentes variáveis técnicas sobre a produtividade ou capacidade de 
produção desses equipamentos, e desenvolver modelos matemáticos que permitissem a predição da produtividade esperada para um "harvester" em determinadas condições de trabalho. Para tanto, foram coletados dados referentes a mais de 4 milhões de $\mathrm{m}^{3}$ de madeira de eucalipto colhidos em primeira rotação e 200 mil horas de trabalho realizado por 69 "harvesters", totalizando mais de 14 mil linhas de dados, junto às empresas Duratex S.A., Votorantim Celulose e Papel, Cia. Suzano de Papel e Celulose e Aracruz Celulose S.A. A partir desses dados foram montadas duas planilhas, uma para colheita e processamento sem descascamento da madeira, e outra para colheita com descascamento realizado pelo "harvester". O volume individual médio das árvores foi a variável que, isoladamente, melhor explicou a capacidade produtiva dos "harvesters", seguida do DAP médio, da altura média e do volume de madeira por hectare. Através de regressões lineares múltiplas foram obtidos modelos mais precisos para cada sistema de trabalho, com ou sem descascamento de madeira, com coeficientes de determinação superiores a 0,75 . 


\title{
QUANTIFICATION AND DETERMINATION OF INFLUENCY FACTORS OVER HARVESTERS PRODUCTIVITY ON LOGGING
}

\author{
Author: MARCELO BRAMUCCI \\ Adviser: Prof. Dr. FERNANDO SEIXAS
}

\section{SUMMARY}

The Brazilian cellulose and paper industry has been total sales of US\$ 7.5 billions on 2000, with consume of 14 millions of $\mathrm{m}^{3}$ of eucalypt wood. Logging and wood transportation are responsible for $50 \%$ of final cost of wood. On cut-to-length system, the harvester is the main machine used on felling and processing of wood. This is an equipment with high cost and technology, justifying studies to improve the planning and precision of operations for obtainment of the best use of machines, with low number of work hours. This work aimed, based on industry data bank, to analyze the kind of influence of different technical variables about the productivity of these equipments and obtain mathematic models to predict the expected productivity for a harvester on different work conditions. It was picked up data from Duratex S.A., 
Votorantim Cellulose and Paper, Cia. Suzano of Paper and Cellulose and Aracruz Celulose S.A. It was done two spreadsheets, one for harvesting and processing with no debarking, and other for processing with debarking done by harvester. This study analyzed data referent of more than 4 millions $\mathrm{m}^{3}$ of eucalypt wood harvested on first rotation and 200 thousand hours of work by 69 harvesters, totalizing more than 14 thousand of data lines. Average individual volume was the variable that, isolated, better explain harvester productivity; followed by mean $\mathrm{DBH}$, mean height and volume of wood per hectare. More precise models were obtained for different work systems (i.e. with or without wood debarking) with determination coefficient higher than 0.75 , by multiple linear regression. 


\section{INTRODUÇÃO}

A mecanização dos processos de colheita e transporte florestal intensificoutse no Brasil a partir do início da década de 90 , com a abertura do mercado brasileiro à importação de máquinas e equipamentos já desenvolvidos e aprimorados em países com maior tradição na colheita florestal.

Desde então, esse processo vem se mostrando irreversível no Brasil, principalmente em função da redução da dependência de mão de obra, melhoria das condições de trabalho, redução do custo final da madeira posto fábrica e da necessidade, por parte das indústrias, de um fornecimento regular e em quantidades cada vez maiores de madeira. No ano de 2000 o setor de papel e celulose brasileiro obteve um faturamento de US\$ 7,5 bilhões, com um consumo total de aproximadamente 14,5 milhões de $\mathrm{m}^{3}$ de madeira.

Apesar da pouca quantidade de estudos realizados no Brasil a respeito desse tipo de operação, diversas empresas brasileiras vêm obtendo sucesso na implementação de sistemas mecanizados de colheita de madeira. Considerando-se que os processos de colheita e transporte da madeira chegam a responder por a 50\% do custo final da madeira posto fábrica (Equipe Técnica da Duratex, 1999a; Wadouski, 1997), qualquer

redução no custo destes processos é importante, no sentido de aumentar a 
competitividade das empresas florestais tanto no mercado interno como no externo. A substituição do sistema semi- mecanizado (motosserra + trator agrícola e carreta) pelo sistema mecanizado (exemplo: "harvester" + "forwarder"), já representa uma redução significativa nos custos em várias empresas. Como exemplos, a Duratex conseguiu uma redução de $6,7 \%$ no custo de produção e de $83,1 \%$ na quantidade de mão de obra empregada na colheita (Equipe Técnica da Duratex, 1999b). A Champion Papel e Celulose Ltda. obteve uma redução de $42 \%$ no custo final da madeira e $60 \%$ no uso de mão de obra (Freitas \& Antiqueira, 1993), e a Votorantim Papel e Celulose reduziu em $\mathrm{R} \$ 4,50 \mathrm{~m}^{-3} \mathrm{o}$ custo final da madeira posto fábrica (Salmeron \& Ribeiro, 1999).

A utilização de sistemas mecanizados para colheita de madeira é afetada por diversas variáveis que interferem na capacidade operacional dos equipamentos e, conseqüentemente, no custo final da madeira. No Brasil, existem ainda poucos dados a respeito da real influência destas variáveis e da capacidade produtiva que se pode esperar dos equipamentos em determinadas condições de trabalho. As estimativas de produtividade e custo baseadas em dados fornecidos pelos fabricantes dos equipamentos, ou obtidas em trabalhos realizados em outros países, mostram-se bastante frágeis, uma vez que refletem dados obtidos em condições totalmente diversas, no que diz respeito ao sistema silvicultural, clima e formação profissional do operador, ficando clara a necessidade da realização de estudos específicos para as condições brasileiras.

Para a realização desse estudo, optou-se pela análise dos dados coletados pelas empresas que utilizam esse tipo de equipamento, em função da grande quantidade acumulada, do baixo custo de aquisição e análise, pela inexistência, na literatura, de trabalhos desse tipo no setor florestal, e, principalmente, por esses dados refletirem a 
realidade operacional das empresas e não de valores obtidos em pequenas parcelas sob condições controladas.

O objetivo deste trabalho foi, a partir dos dados obtidos junto a empresas florestais que utilizam "harvesters" na colheita e processamento de madeira, verificar quais as principais variáveis técnicas que interferem na capacidade produtiva desses equipamentos e elaborar funções matemáticas que permitam predizer, de acordo com as diferentes condições de trabalho, a produtividade para o corte e processamento da madeira por meio de "harvesters". Tais equações permitirão um planejamento mais preciso da atividade de colheita mecanizada de madeira, resultando em um melhor aproveitamento dos recursos disponíveis.

A hipótese inicial é de que o volume individual das árvores é o fator que tem maior influência sobre a produtividade dos equipamentos e que, mesmo assim, não explica, isoladamente, as produtividades alcançadas. Em função disso será necessária a inclusão de outras variáveis, como densidade de plantio, declividade do terreno e tipo de equipamento, para maior exatidão dos modelos. 


\section{REVISÃO DE LITERATURA}

A atividade florestal instalourse no país nos primeiros anos após seu descobrimento, por meio da exploração do pautbrasil, e por muito tempo constituiu-se na principal atividade econômica. Com o desenvolvimento da agricultura, foi relegada a segundo plano na economia brasileira e só a partir da década de 60, com a implementação dos incentivos fiscais, o reflorestamento tornourse uma atividade em larga escala (Siqueira, 1990).

No Brasil, a modernização das operações florestais, principalmente as referentes à colheita e transporte, iniciourse na década de 70, quando a indústria nacional começou a produzir maquinários como motosserras e gruas (Sales, 1981).

A colheita florestal sempre foi uma atividade objeto de especial atenção nas empresas consumidoras de madeira, dada a sua alta representatividade nos custos de produção e elevada demanda de mão-de-obra, além da natureza desgastante do trabalho e do elevado nível de risco de acidentes (Equipe Técnica da Duratex, 1999b).

De um modo geral, a atividade de corte de madeira semi-mecanizada é realizada através de motosserras, no arranjamento das toras utilizam-se machados, e o descascamento é realizado através de facões (Salmeron \& Ribeiro, 1997).

Com a abertura das importações, no início da década de 90, boa parte das empresas florestais brasileiras intensificou o processo de mecanização da colheita. Geralmente, 
essas empresas registraram ganhos expressivos na utilização de mão-de-obra e redução da frequiência e gravidade dos acidentes de trabalho. Desde então, verifica-se um contínuo aumento no grau de mecanização no país.

Os sistemas de colheita mecanizada no Brasil podem ser agrupados em dois grandes grupos: a) sistemas de "toras curtas", onde todo o processamento da madeira é feito no canteiro de corte; e b) sistemas de "toras longas", onde a árvore derrubada é eventualmente desgalhada no local de abate e a madeira posteriormente desdobrada à margem dos carreadores (Seixas, 1998).

Em diversos sistemas de toras curtas, o "harvester" é a máquina principal, utilizada na derrubada e processamento, que consiste, em alguns casos no descascamento das árvores, no desgalhamento e no corte em toras de comprimento pré-determinado, deixando as toras agrupadas e prontas para serem retiradas da área de plantio. Trata-se de um equipamento autopropelido, constituído por um conjunto motriz de alta mobilidade dentro da floresta e boa estabilidade, um braço hidráulico e um cabeçote processador (Amabilini, 1991). Por trabalhar em regime de campo, sua capacidade produtiva é fortemente influenciada por um grande número de fatores ambientais e técnicos. Os principais fatores que influenciam a colheita de madeira são: o clima (chuva e ventos), a capacidade de suporte do terreno, topografia, características das árvores quanto ao diâmetro, tamanho dos galhos e da copa, peso e qualidade da madeira (Seixas, 1998).

Para que se obtenha a maior eficiência possível de um sistema de colheita de madeira, o levantamento das condições encontradas no ambiente de trabalho é fundamental. A análise dos dados coletados permitiria determinar os limites 
operacionais para cada tipo de equipamento a ser utilizado, bem como definir a metodologia operacional mais adequada na viabilização do sistema como um todo.

De um modo geral, a produtividade do corte mecanizado é muito influenciada pelo volume individual da árvore, de maneira que o rendimento da colheita acompanha proporcionalmente o volume individual das árvores, quando este está entre 0,08 e 0,15 $\mathrm{m}^{3}$ com casca (Equipe Técnica da Duratex, 1999b). Holtzscher \& Lanford (1997), estudando o efeito do diâmetro à altura do peito (DAP) sobre custo e produtividade da colheita mecanizada, encontraram alta correlação entre tais fatores, de modo que, à medida que crescia o diâmetro médio das árvores, aumentava a produtividade do sistema e, conseqüentemente, caiam os custos operacionais. Além de interferir no custo da operação de colheita, a produtividade da floresta que está sendo explorada, interfere da mesma forma na operação seguinte, ou seja, a extração da madeira, quer seja ela feita através de arraste (Valverde et al., 1996), ou através de baldeio (Santos et al., 1995), mostrando-se, portanto, o fator preponderante na formação dos custos finais da madeira.

Estudando a utilização de processadores mecânicos na operação de desgalhamento e toragem de eucalipto, Santos \& Machado (1995) observaram que a capacidade produtiva do equipamento crescia à medida que aumentava o volume por árvore até atingir um ponto máximo, com um volume por árvore de $0,34 \mathrm{~m}^{3}$, decrescendo após esse valor. O custo do processamento teve comportamento exatamente inverso. Vale ressaltar ainda que os autores demonstraram que os gastos com peças e mão-de-obra de oficina corresponderam a 42,6 \% do custo operacional do equipamento.

Avaliando a performance de um "harvester" TIMBCO T425 equipado com cabeçote ULTIMATE 5600 , Huyler \& LeDoux (1999) observaram que a capacidade 
produtiva da máquina, em volume de madeira, crescia proporcionalmente ao volume de madeira por árvore e o custo por unidade de volume seguia a tendência inversa.

Salmeron \& Ribeiro (1997), comparando a capacidade produtiva de "harvesters" em declividades de até $65 \%$, trabalhando com comprimentos de toras de 2,2 e 5,7m, obtiveram produtividades de 13,39 e $19,17 \mathrm{~m}^{3} \mathrm{~h}^{-1}$, respectivamente.

Tiburcio et al. (1995), avaliando diferentes sistemas de corte, processamento e baldeio de Eucalyptus grandis de 5,7 anos, obtiveram para o "harvester" uma produtividade de $23,6 \mathrm{~m}^{3} \mathrm{~h}^{-1}$, trabalhando com três linhas de plantio simultaneamente, e $25 \mathrm{~m}^{3} \mathrm{~h}^{-1}$, com cinco linhas de plantio. Os autores consideraram o sistema de três linhas como o mais viável, por razões de segurança operacional.

Em estudos do "Forest Engineering Institute of Canada" (FERIC) sobre o desempenho de "harvesters" e processadores mecânicos, Richardson \& Makkonen (1994) concluíram que o fator que mais afetava a capacidade produtiva para ambas as máquinas era o volume médio por árvore, seguido pela razão entre o número de árvores comerciais e não-comerciais por hectare e também pelo tempo de experiência do operador.

Bulley (1999), estudando em floresta de regeneração natural o efeito do tamanho das árvores e da densidade da floresta sobre a produtividade de dois modelos de "harvesters" (Timberjack 608 e Rocan-T) e de "forwarders" (Timberjack 1210 e Rottne Rapid 6WD), concluiu que apenas o tamanho das árvores influenciou a capacidade produtiva dos "harvesters", sendo que quanto maior o volume maior a produtividade. Já no caso dos "forwarders", a capacidade produtiva foi influenciada apenas pela distância de transporte. 
Gingras (1992) avaliou a utilização de um cabeçote processador "KETO 150”, montado em uma máquina base de esteiras, na derrubada de árvores em um sistema de toras longas, ou seja, sem processar a madeira. Observou uma produtividade de 90 árvores ou $20 \mathrm{~m}^{3}$ de madeira por hora efetivamente trabalhada, com um custo aproximado de $\mathrm{C} \$ 4,35 \mathrm{~m}^{-3}$.

Hunt (1992) avaliou a utilização de um "harvester" VALMET 546 no primeiro desbaste em uma floresta com 4300 árvores $\mathrm{ha}^{-1}$. Foi observada uma eficiência de $80 \%$, uma capacidade produtiva de $10 \mathrm{~m}^{3}$ de madeira por hora efetivamente trabalhada e um custo, incluindo derrubada, traçamento e transporte, de C\$25,00 $\mathrm{m}^{-3}$.

Plamondon (1993) avaliou o desempenho de um "harvester" ULTIMATE 4500, em uma floresta com 400 a 560 árvores comerciais por hectare, derrubando, desgalhando e destopando as árvores. A máquina apresentou uma produtividade de 109 árvores $\mathrm{h}^{-1}$ nessas condições, equivalendo a $13 \mathrm{~m}^{3}$ por hora trabalhada, gerando um custo de $\mathrm{C} \$ 9,10 \mathrm{~m}^{-3}$.

Richardson \& Gingras (1995) analisaram a capacidade produtiva de um "harvester" VALMET 701 equipado com cabeçote "Pan 626" em primeiro desbaste e com cabeçote "Pan 828" em operação de colheita comercial. Foram obtidos as produtividades e custos com operadores experientes e inexperientes e em um ou dois turnos de trabalho. No primeiro desbaste, o operador experiente conseguiu derrubar e processar $5,8 \mathrm{~m}^{3}$ de madeira por hora trabalhada contra $5,1 \mathrm{~m}^{3}$ por hora do operador inexperiente, sendo que no corte comercial foram produzidos 8,2 e $6,2 \mathrm{~m}^{3}$, respectivamente. Os custos variaram entre $C \$ 10,00$ e $C \$ 16,00$ por $\mathrm{m}^{3}$ de madeira, sendo que o trabalho em dois turnos sempre apresentou valores inferiores. 
Mitchell (1995), também analisando um "harvester" VALMET 546, obteve uma capacidade produtiva de $21,2 \mathrm{~m}^{3}$ por hora trabalhada, processando-se a madeira e separando as toras para celulose e serraria.

Ewing \& Lirette (1995) estudaram um “harvester” VALMET 544H em operação de corte comercial seletivo em uma floresta com 1620 árvores ha $^{-1}$ inicialmente e 727 árvores $\mathrm{ha}^{-1}$ depois do tratamento. $\mathrm{O}$ equipamento alcançou uma capacidade produtiva de 85,4 árvores por hora, gerando $12 \mathrm{~m}^{3}$ de madeira por hora trabalhada, com um custo de colheita estimado em C\$9,32 $\mathrm{m}^{-3}$, considerada uma eficiência de $80 \%$.

Godin (1996) comparou três "harvesters" diferentes operando em uma floresta com baixo volume por árvore e que foi afetada por uma tempestade, resultando na quebra de $50 \%$ das árvores. Os equipamentos testados e respectivos rendimentos foram: Hyundai R130LC/cabeçote Fabtek 41 com 129 árvores $\mathrm{h}^{-1}$ e 4,73 $\mathrm{m}^{3} \mathrm{~h}^{-1}$; Caterpillar 320L/cabeçote Ultimate 4500 com 155 árvores $\mathrm{h}^{-1}$ e $6,8 \mathrm{~m}^{3} \mathrm{~h}^{-1}$; Roçam T/cabeçote Pan GM828 ESB com 189 árvores $\mathrm{h}^{-1}$ e $6,7 \mathrm{~m}^{3} \mathrm{~h}^{-1}$.

Ewing \& Lirette (1999) estudaram a produtividade de um "harvester" VALMET 901C, trabalhando em área com declividade até 30\% e com grande acúmulo de neve. A floresta contava inicialmente com 2920 árvores comerciais por hectare, tendo sido realizado um desbaste de $50 \%$. O equipamento apresentou uma capacidade produtiva de 80 árvores ou $4,6 \mathrm{~m}^{3}$ por hora efetivamente trabalhada, com um custo de colheita de C\$ $26,93 \mathrm{~m}^{-3}$.

Gingras (1998) desenvolveu um estudo aprofundado sobre o efeito dos fatores de sítio e talhão na performance do "feller-buncher" em floresta nativa. Os fatores analisados foram: 
- características do terreno como firmeza, presença de obstáculos e declividade que interferem principalmente na velocidade de deslocamento do equipamento;

- características da floresta como visibilidade, onde a presença de galhos baixos ou sub-bosque dificultam a operação do equipamento; distribuição das árvores comerciais no talhão; produtividade e volume por árvore.

$\mathrm{O}$ autor concluiu que os fatores que exerceram maior influência foram o diâmetro médio das árvores, o número de árvores acumuladas por ciclo e a razão entre árvores não comerciais e comerciais.

Construindo um modelo matemático para simulação de colheita florestal através de "harvesters", Eliasson (1999) observou que o tempo gasto pelo "harvester" para mover-se e para a derrubada da árvore, praticamente não se altera em função do aumento da distância entre as árvores. Já os tempos gastos com o corte, a derrubada e o processamento crescem proporcionalmente ao DAP das árvores. Por outro lado, a capacidade produtiva em volume de madeira por hora cresce proporcionalmente ao aumento do volume individual das árvores derrubadas.

Em um estudo comparativo entre "harvesters" com diferentes capacidades de corte (um até $350 \mathrm{~mm}$ de diâmetro e outro até $600 \mathrm{~mm}$ ), Iwaoka et al. (1999) não encontraram diferença significativa entre os rendimentos. Ressaltou, entretanto, o menor impacto ambiental e o menor custo de aquisição e de manutenção das máquinas de menor porte.

No que diz respeito à interferência da experiência do operador na capacidade produtiva dos "harvesters", McConchie \& Evanson (1996) relataram que de 212 
trabalhos publicados na Nova Zelândia sobre mecanização florestal, apenas oito tratavam da influência dos aspectos humanos sobre a operação de colheita florestal mecanizada. A operação de um "harvester" é um trabalho complexo, que envolve contínuas tomadas de decisão e rápidos movimentos manuais nos controles, e por isso a habilidade do operador tem grande influência sobre a produtividade do equipamento (Richardson \& Makkonen, 1994).

Estudando a capacidade produtiva de "harvesters" operados por iniciantes, Parker (1996) relatou que durante os 30 primeiros dias de trabalho havia um grande aumento na capacidade produtiva, reduzindo-se sempre que ocorria alguma mudança nas condições de trabalho e voltando logo depois à normalidade. Entretanto, foram considerados apenas os 400 primeiros dias de trabalho neste estudo. Seriam necessárias comparações entre operadores com maior ou menor tempo de experiência, uma vez que o nível de treinamento do operador pode ter grande influência sobre a produtividade do "harvester".

Nota-se na literatura existente uma clara deficiência de informações sobre o grau de influência dos diversos fatores que afetam a capacidade produtiva do "harvester" na operação de colheita forestal mecanizada da forma como é feita no Brasil. Assim sendo, torna-se necessária a realização de um estudo que leve em consideração as nossas condições de trabalho. Tais informações, quando disponibilizadas, permitirão um planejamento mais adequado dessas operações por parte das empresas florestais, reduzindo os custos e conseqüente aumento da competitividade. 


\section{MATERIAL E MÉTODOS}

\subsection{Levantamento de informações junto às empresas florestais}

A utilização dos bancos de dados das empresas que utilizam "harvesters" na colheita florestal resultou em grande economia de tempo e dinheiro para a obtenção dos dados, principalmente quando se leva em conta a intensidade de amostragem obtida. Foram obtidas informações referentes à colheita e processamento de mais de $4.000 .000 \mathrm{~m}^{3}$ de madeira (aproximadamente $30 \%$ de toda madeira de eucalipto consumida no país durante o ano de 2000) em 200.000 horas de trabalho realizado por 69 "harvesters" de diferentes marcas e modelos, dando origem a mais de 14.000 linhas de dados.

Foram analisadas apenas as produtividades alcançadas pelos "harvesters" na colheita de plantios homogêneos de Eucalyptus spp. em primeira rotação durante o ano de 2000 na maior parte das empresas e dados de 1999 e 2000 da Cia Suzano de Papel e Celulose.

Foram coletados dados das seguintes empresas:

\subsubsection{Companhia Suzano de Papel e Celulose}

A Cia Suzano Papel e Celulose é hoje a maior fabricante integrada de celulose e papel de eucalipto do país, somadas as produções das empresas Suzano Papel e Bahia 
Sul. Conta atualmente com 3.500 funcionários e detém 16,6 \% da produção brasileira de papel para escrita e impressão, 29\% da produção nacional de papel-cartão de primeira linha e $8,9 \%$ do mercado de celulose, no qual trabalha com excedente de produção.

A unidade estudada localiza-se na cidade de Suzano, região leste do Estado de São Paulo, no Vale do Paraíba. Conta com apenas um "harvester" em operação na região de Suzano, sendo que até o final de 1999 a empresa utilizava um equipamento constituído de uma máquina base "Caterpillar 320”, escavadeira hidráulica com 95,5kW de potência motora e $20.400 \mathrm{~kg}$ com esteiras de $600 \mathrm{~mm}$, equipada com cabeçote da marca "Husk" com diâmetro máximo de corte de $450 \mathrm{~mm}$. Até então a empresa transportava a madeira com casca. No início de 2000 este equipamento foi substituído por uma máquina base “Volvo EC200", escavadeira hidráulica de 107kW, 20.500kg e esteiras de 600mm, equipada com cabeçote "Votec W-650” com capacidade para até $650 \mathrm{~mm}$ de diâmetro. A partir daí, a empresa passou a descascar a madeira no campo com o "harvester" produzindo toras com $4,4 \mathrm{~m}$.

As áreas de plantio na região são compostas por solos de boa fertilidade e dispostos em relevo que varia de plano a forte-ondulado, num total de 9.100 ha.

\subsubsection{Duratex S.A.}

Empresa produtora de chapas de fibra, aglomerados e madeira serrada, com fábricas em Jundiaí, Botucatu, Agudos e Itapetininga, no Estado de São Paulo. Possui áreas de plantio de eucalipto e pinus nas quatro regiões, totalizando 106.000ha, em áreas planas a suave-onduladas e solos de média a boa fertilidade, com colheita 100\% 
mecanizada, processando toras com 6m. Em 2000 contava com 17 "harvesters" de diferentes marcas e modelos, a seguir:

- Uma máquina "Sisu Valmet 601” 4x4 com 95kW de potência e 13.600kg, equipada com cabeçote "Valmet 960" de 1.155kg e 600mm de diâmetro máximo de corte (figura 1);

- Duas máquinas "Sisu Valmet 601” 6x6 com 128kW de potência e 16.900kg equipadas com cabeçotes "Valmet $960 "$ de $1.155 \mathrm{~kg}$ e $600 \mathrm{~mm}$ de diâmetro máximo de corte;

- Uma máquina "Bell” de esteiras equipada com cabeçote harvester;

- Duas máquinas “Caterpillar 320”, escavadeira hidráulica com 95,5kW de potência motora e $20.400 \mathrm{~kg}$, com esteiras de $600 \mathrm{~mm}$, equipadas com cabeçotes "Valmet 960 " de $1.155 \mathrm{~kg}$ e $600 \mathrm{~mm}$ de diâmetro máximo de corte;

- Duas máquinas “Caterpillar 320”, escavadeira hidráulica com 95,5kW de potência motora e $20.400 \mathrm{~kg}$, com esteiras de $600 \mathrm{~mm}$, equipadas com cabeçotes "Valmet 965 " de $1.255 \mathrm{~kg}$ e $650 \mathrm{~mm}$ de diâmetro máximo de corte;

- Cinco máquinas “Timberjack 608” de esteiras com $125 \mathrm{~kW}$ e $19.300 \mathrm{~kg}$, equipadas com cabeçote tipo "Slingshot" da marca "Risley", com disco de corte de 21 " e $2.630 \mathrm{~kg}$ (figura 2);

- Três máquinas “Caterpillar 320”, escavadeira hidráulica com 95,5kW de potência motora e $20.400 \mathrm{~kg}$, com esteiras de $600 \mathrm{~mm}$, equipadas com cabeçote tipo "Slingshot" da marca "Risley" com disco de corte de 21 " e $2.630 \mathrm{~kg}$.

O cabeçote processador tipo "Slingshot" foi originalmente desenvolvido para operar em colheita de florestas com baixo volume por fuste, especialmente em segunda rotação, processando varias árvores simultaneamente. Entretanto, os dados utilizados no presente trabalho referem-se à utilização destes cabeçotes apenas em florestas em primeira rotação. 


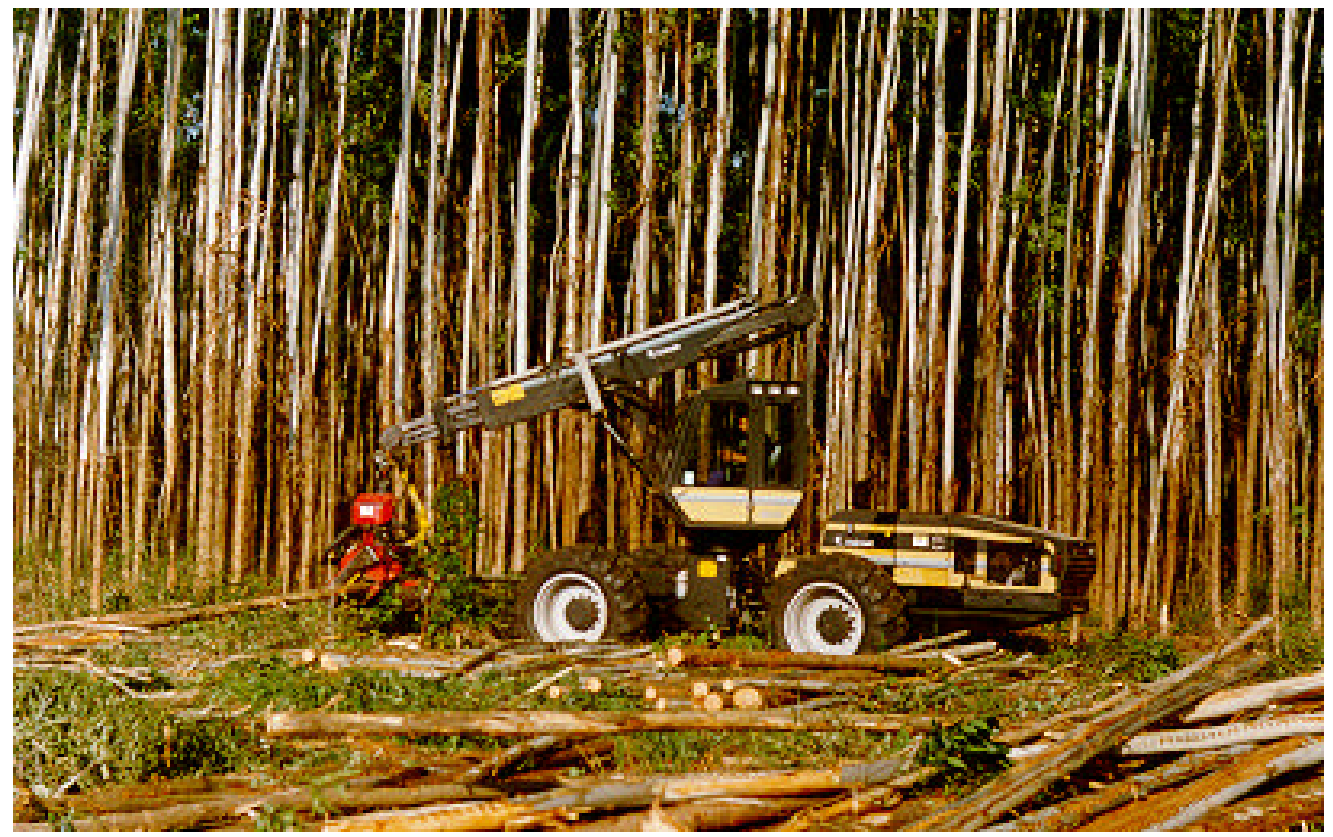

Figura 1 - Harvest Valmet 601 4x4 equipado com cabeçote processador Valmet 960.

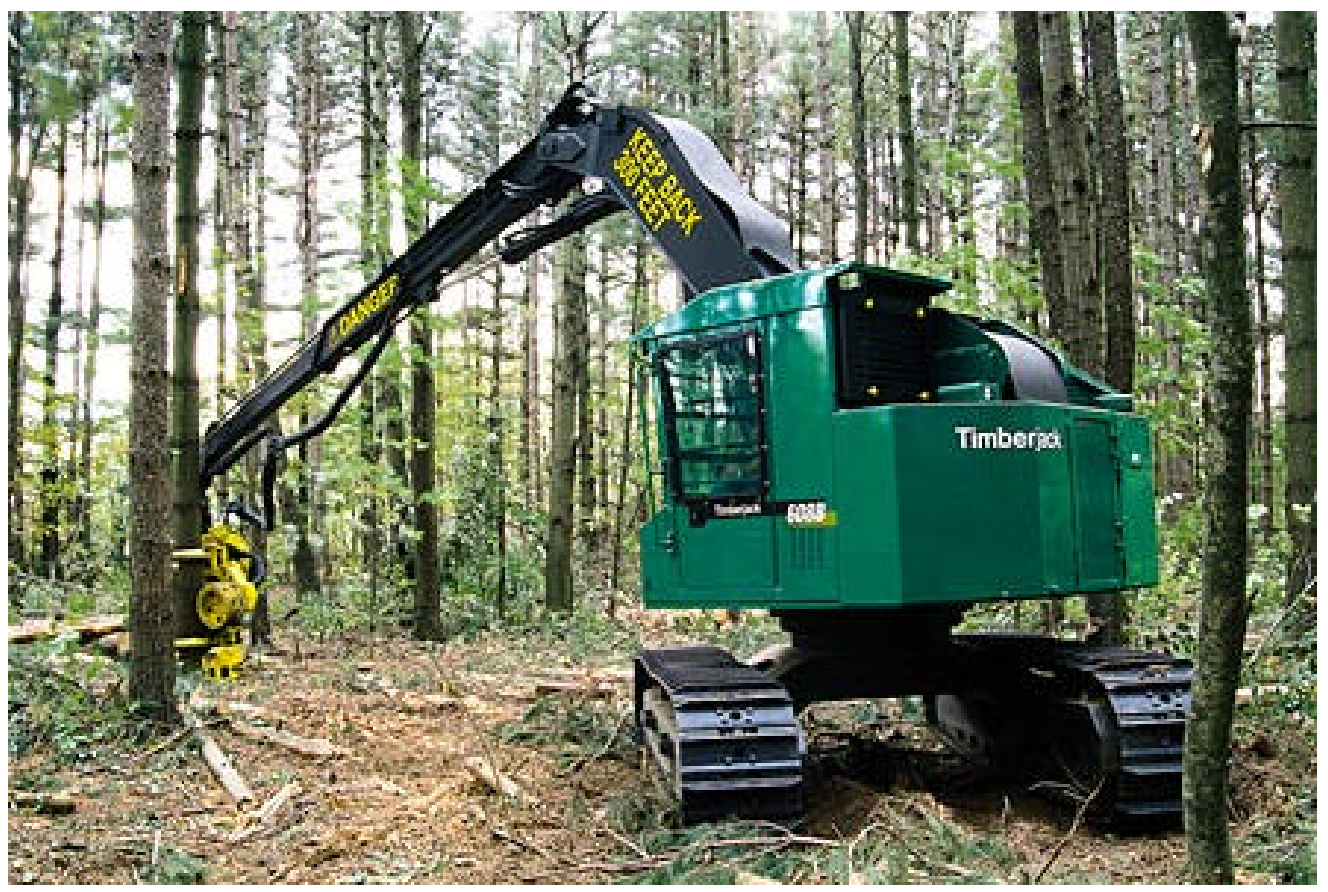

Figura 2 - Harvester Timberjack 608 de esteiras. 


\subsubsection{Votorantim Celulose e Papel}

Com fábricas localizadas nos municípios de Jacareí, Luiz Antônio e Piracicaba, Estado de São Paulo, responde por $23 \%$ da celulose de eucalipto fornecida ao mercado nacional. Possui florestas localizadas no Vale do Paraíba, na região de Ribeirão Preto, na área central do Estado de São Paulo e em Capão Bonito, ao Sul do Estado. Conta com área total de 160.000 ha e área de plantio efetivo de eucalipto de 107.000 ha, com raio médio de distância fábrica/florestas de $160 \mathrm{~km}$.

No presente trabalho foram considerados apenas dados da unidade de Jacareí, com 33.000ha, em função do maior grau de mecanização da colheita (75\%) e da maior declividade das áreas de plantio. No ano de 2000 a unidade de Jacareí contava com dez "harvesters", processando e descascando toras de 5,5m, listados a seguir:

- Oito máquinas da marca “Timberjack 1270B" 6x6 com 163kW e 16.500kg, equipados com cabeçotes 762C (figura 3), da mesma marca, com 650mm de diâmetro máximo de corte e $1.350 \mathrm{~kg}$;

- Duas máquinas da marca “Timberjack 2618” de esteiras com nivelamento automático da cabine, $153 \mathrm{~kW}$ e $23.000 \mathrm{~kg}$, equipados com cabeçotes $762 \mathrm{C}$, da mesma marca, com $650 \mathrm{~mm}$ de diâmetro máximo de corte e $1.350 \mathrm{~kg}$. 


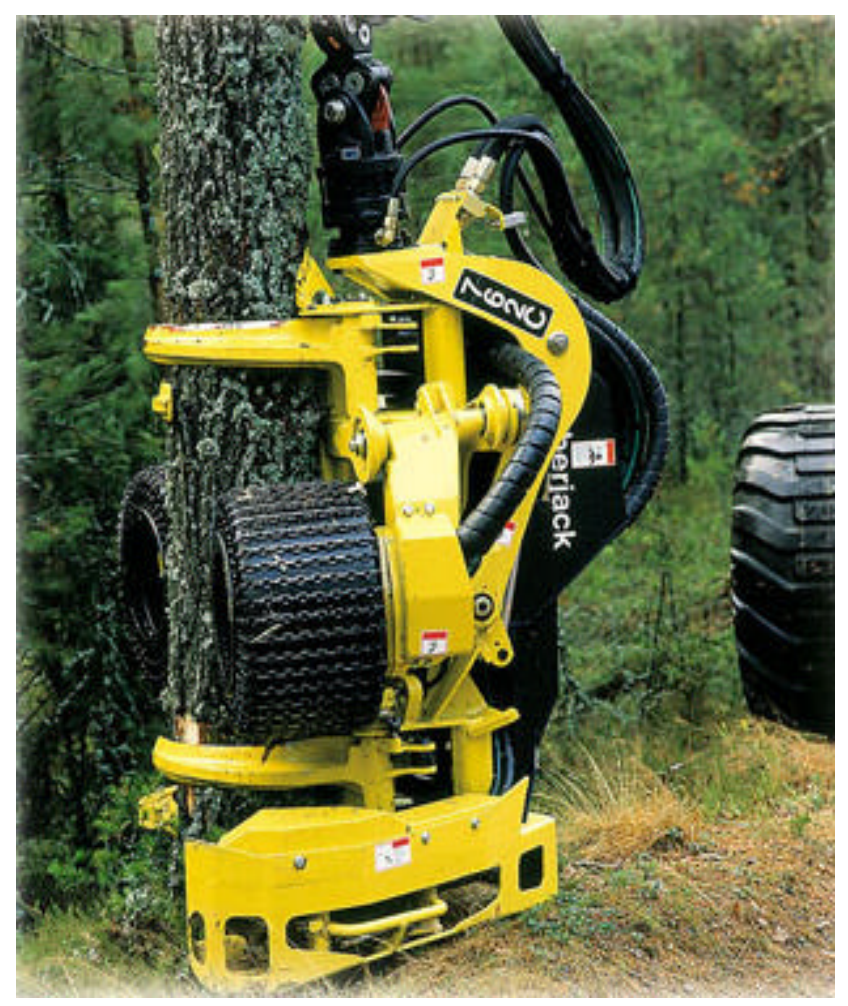

Figura 3 - Cabeçote processador Timberjack 762 C

\subsubsection{Aracruz Celulose S.A.}

A Aracruz Celulose é a maior produtora mundial de celulose branqueada de eucalipto, vendida globalmente para fabricantes de papéis sanitários, de impressão e de escrever, e papéis especiais.

As operações florestais da Aracruz abrangem 144.000ha de plantios de eucalipto nos Estados do Espírito Santo e Bahia, em solos de média produtividade e relevo variando de plano a suave-ondulado, intercalados com 66.000ha de reservas nativas de propriedade da empresa. 
A fábrica, localizada no município de Aracruz, ES, tem duas linhas de produção, com capacidade total de 1,3 milhão de toneladas anuais de celulose, e uma terceira linha em construção.

No ano de 2000 a empresa contava com 42 "harvesters" que responderam por $90 \%$ de toda madeira colhida pela empresa. Aproximadamente metade da madeira foi colhida e processada sem o descascamento feito pelo "harvester", e a outra metade foi descascada. Nos dois casos, as toras foram cortadas com 6 metros. Os $10 \%$ restantes, localizados geralmente em grotas e regiões mais declivosas, foram colhidos por sistema semi- mecanizado.

Os equipamentos da empresa eram de três marcas e modelos diferentes listados a seguir:

- Onze máquinas “Caterpillar 320”, escavadeira hidráulica com 95,5kW de potência motora e $20.400 \mathrm{~kg}$ com esteiras de $600 \mathrm{~mm}$ equipadas com cabeçotes "Sisu-Valmet 965”, de $1.255 \mathrm{~kg}$ e $650 \mathrm{~mm}$ de diâmetro máximo de corte;

- Seis máquinas "Fiat FH200”, escavadeira hidráulica com 105 kW de potência motora e $21.000 \mathrm{~kg}$ com esteiras de $650 \mathrm{~mm}$ equipadas com cabeçotes "Sisur Valmet 965”, de $1.255 \mathrm{~kg}$ e $650 \mathrm{~mm}$ de diâmetro máximo de corte;

- Vinte e cinco máquinas “Volvo EC200”, escavadeira hidráulica de 107kW, 20.500kg e esteiras de $600 \mathrm{~mm}$, equipadas com cabeçote "Votec W-650" com capacidade para até $650 \mathrm{~mm}$ de diâmetro. 


\subsection{Variáveis de influência}

Foram coletadas todas as informações presentes nos bancos de dados das empresas visitadas, referentes à capacidade produtiva dos "harvesters" e às condições encontradas na ocasião da colheita. Foram obtidos dados referentes a: empresa, fazenda, talhão, máquina, operador, tempo efetivo gasto e número de árvores colhidas. A partir desses valores, foram obtidas as produtividades efetivas das diferentes combinações de operador, máquina e talhão. As produtividades obtidas foram confrontadas com todas as varáveis disponíveis, relacionadas a seguir:

Quanto à floresta:

- Diâmetro à Altura do Peito (DAP) médio (cm);

- altura média das árvores (m);

- volume médio por árvore ( $\left.\mathrm{m}^{3} / a ́ r v o r e\right) ;$

- número de árvores por hectare;

- produtividade do talhão $\left(\mathrm{m}^{3} / \mathrm{ha}\right)$;

- idade do plantio;

- porcentagem de casca (apenas nos dados da VCP).

Quanto às características técnicas:

- $\quad$ tipo, modelo e idade das máquinas;

- número de combinações máquina/operador por talhão (apenas nos dados da Duratex);

- Índice pluviométrico do mês em que foi realizada a colheita (apenas nos dados da VCP e Aracruz);

- tempo de experiência dos operadores (apenas nos dados da Duratex). 


\subsection{Análise estatística}

Inicialmente os dados foram divididos em duas planilhas diferentes, uma com dados referentes à madeira processada sem descascamento e outra para madeira descascada pelo "harvester" no campo. Essa opção deveu-se à diferença entre os resultados obtidos pelos dois sistemas e à impossibilidade de se analisar dois sistemas diferentes ao mesmo tempo.

As produtividades obtidas foram confrontadas inicialmente com cada uma das variáveis obtidas na forma de regressão. Foram realizados estudos de suposições e análises de variância com a determinação do "Erro Padrão da Média" para as regressões simples, através do módulo "SAS Lab" do programa "SAS". Os gráficos foram construídos através do programa "Microsoft Excel".

Os equipamentos analisados foram, inicialmente, separados por sistema de trabalho e em seguida, agrupados por modelo da máquina base e do cabeçote processador. Os resultados obtidos pelos diferentes grupos foram avaliados por análise de variância e ordenados pelo teste de "Tukey" para comparação de médias, ao nível de 95\% de probabilidade.

Finalmente, foram feitas regressões lineares múltiplas para cada sistema estudado, com a inclusão dos diferentes modelos de equipamentos na forma de variável "Dunmy", com estudo de suposições, através do módulo "SAS Lab" do programa "SAS". 


\section{RESULTADOS E DISCUSSÃO}

Foram incluídos dados referentes a 4,2 milhões de $\mathrm{m}^{3}$ de madeira e 200 mil horas de trabalho. A utilização desse tipo de informação pode te como inconvenientes a forma, nem sempre criteriosa, como os dados são registrados e a grande quantidade de fatores que podem interferir na operação dos equipamentos e que não estão relacionados nos bancos de dados. Entre estes podem ser citados o turno de trabalho, a influência de ventos fortes, pequenos problemas mecânicos que reduzem a capacidade de produção da máquina, mas não a impede de operar, entre outros.

Os dados obtidos foram divididos em duas planilhas diferentes, de acordo com o sistema de trabalho adotado: o primeiro, onde as árvores derrubadas não são descascadas pelos "harvesters", com um total de 7095 linhas de dados, e outro sistema, com 7397 linhas, onde ocorre o descascamento das árvores pelos "harvesters" .

Os estudos de suposições feitos para as regressões simples com todas as variáveis estudadas nos dois sistemas indicaram a necessidade da transformação da variável resposta "Produtividade $\left(\mathrm{m}^{3} / \mathrm{h}\right)$ " em "log da produtividade $\left(\mathrm{m}^{3} / \mathrm{h}\right)$ ", para corrigir problemas de heterogeneidade de variância dos resíduos. E indicaram que o modelo que mais se adequava aos dados era o cúbico, cuja principal característica é um ponto de inflexão ao longo da curva, que se justifica, uma vez que as máquinas possuem limites operacionais a partir dos quais surge a tendência de queda da produtividade. 


\subsection{Regressões simples}

\subsubsection{Volume por árvore}

Segundo a literatura consultada (Santos \& Machado, 1995; Holtzscher \& Lanford, 1997), o volume por árvore é a variável de influência que mais explica as variações nas produtividades obtidas pelos "harvesters". Os resultados obtidos podem ser vistos nas Figuras 4, para madeira não descascada, e 5, para madeira descascada pelos "harvesters".

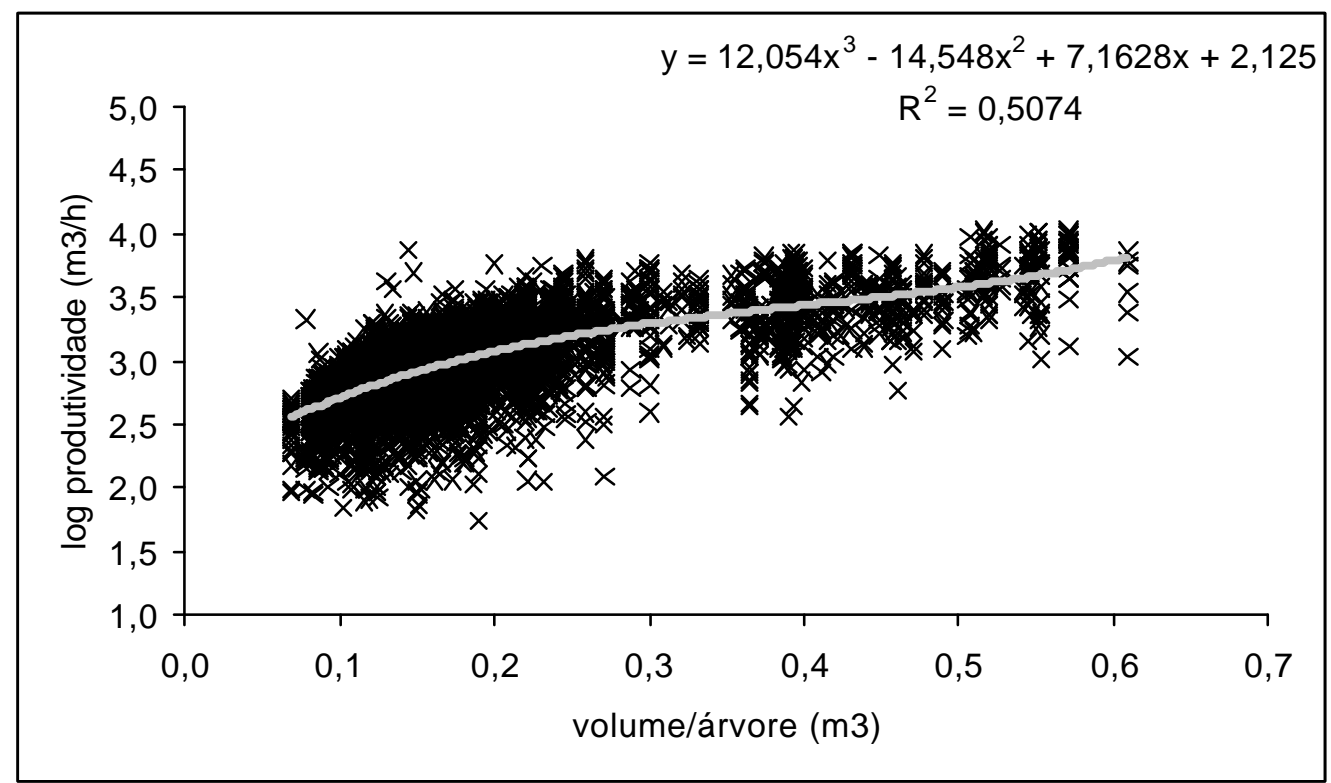

Figura 4 - Gráfico do logaritmo das produtividades dos equipamentos, sem descascamento de madeira, em relação ao volume médio por árvore, com a respectiva linha de tendência, equação de regressão e $\mathrm{R}^{2}$. 


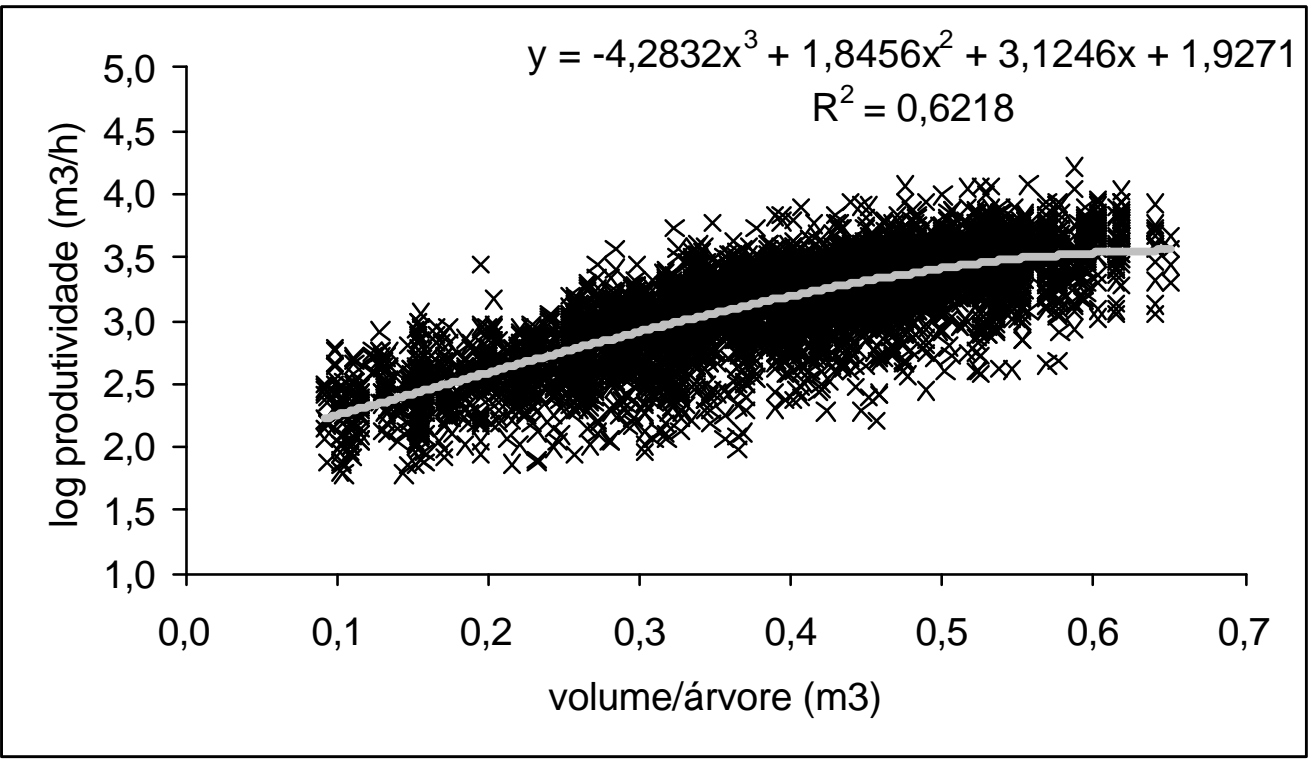

Figura 5 - Gráfico do logaritmo das produtividades dos equipamentos, com descascamento da madeira, em relação ao volume médio por árvore, com a respectiva linha de tendência, equação de regressão e $\mathrm{R}^{2}$.

Como pode ser visto na figura 4, o sistema sem descascamento de madeira apresenta um resultado ligeiramente superior em árvores de menor porte (entre 0,1 e 0,3 $\mathrm{m}^{3}$ ), com um rápido aumento da produtividade dos equipamentos com o aumento do volume individual das árvores dentro dessa faixa. A partir desse volume, o aumento se torna mais lento. Já no sistema com descascamento de madeira, o aumento da produtividade dos equipamentos é praticamente linear até $0,5 \mathrm{~m}^{3}$ por árvore e a partir desse volume existe uma tendência à estabilização da produtividade dos equipamentos.

A menor produtividade do sistema com descascamento de madeira, quando operando em árvores de menor porte, pode ser atribuída ao tempo gasto com o descascamento, que é praticamente o mesmo em árvores de maior ou menor porte, especialmente no que se refere ao diâmetro. 
A variável "volume por árvore" explica boa parte da produtividade alcançada pelas máquinas. Entretanto, isso pode ser atribuído, em parte, ao fato de que o volume de madeira colhido pelos equipamentos é determinado, de forma indireta, pela multiplicação do número de árvores colhidas pelo volume médio das árvores, estimado pelo inventário pré-corte, daí a relação tão estreita entre as variáveis preditora e resposta.

\subsubsection{DAP médio das árvores}

O DAP médio das árvores também é citado na literatura (Eliasson, 1999; Gingras, 1988) como um dos fatores que influenciam fortemente a produtividade de equipamentos de colheita florestal. Os resultados obtidos podem ser vistos nas Figuras 6 e 7 .

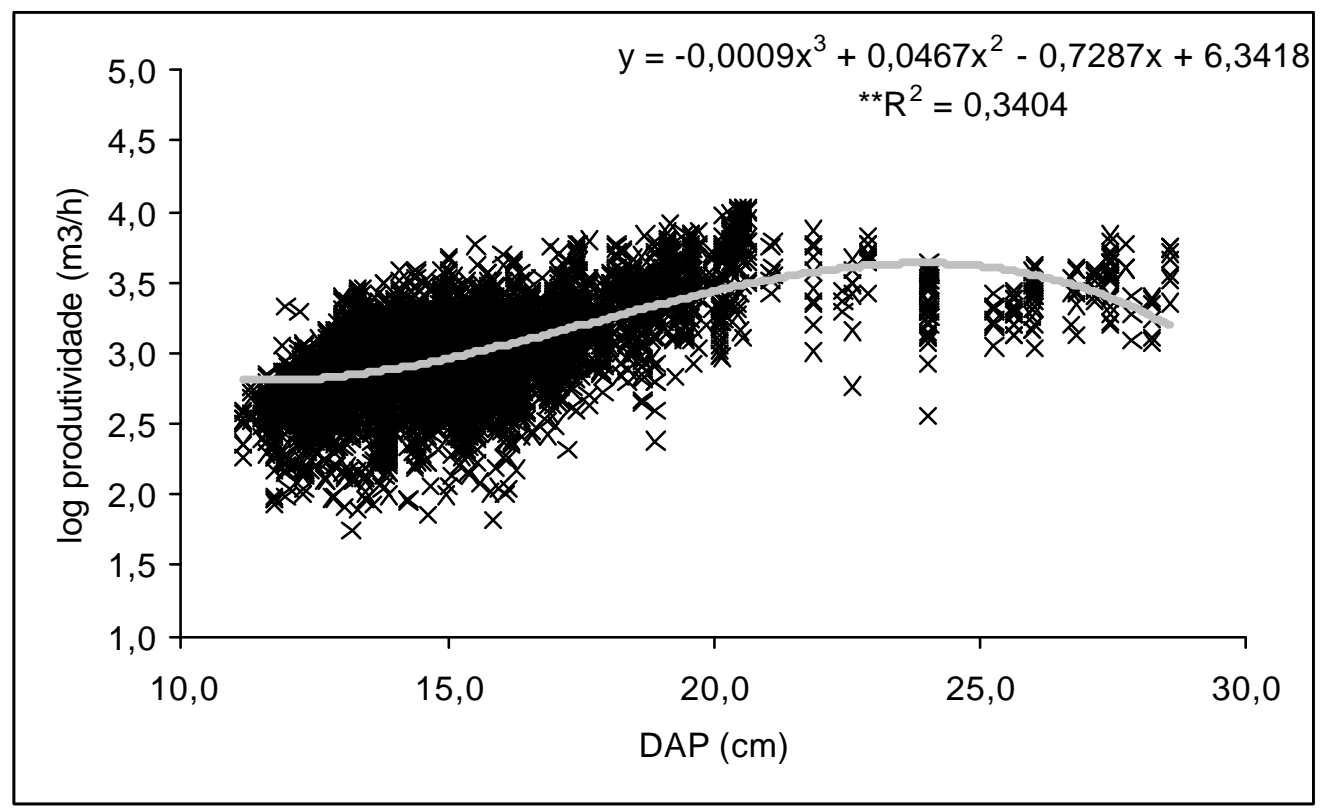

Figura 6 - Gráfico do logaritmo das produtividades dos equipamentos, sem descascamento da madeira, em relação ao DAP médio, com a respectiva linha de tendência, equação de regressão e $\mathrm{R}^{2}$. 


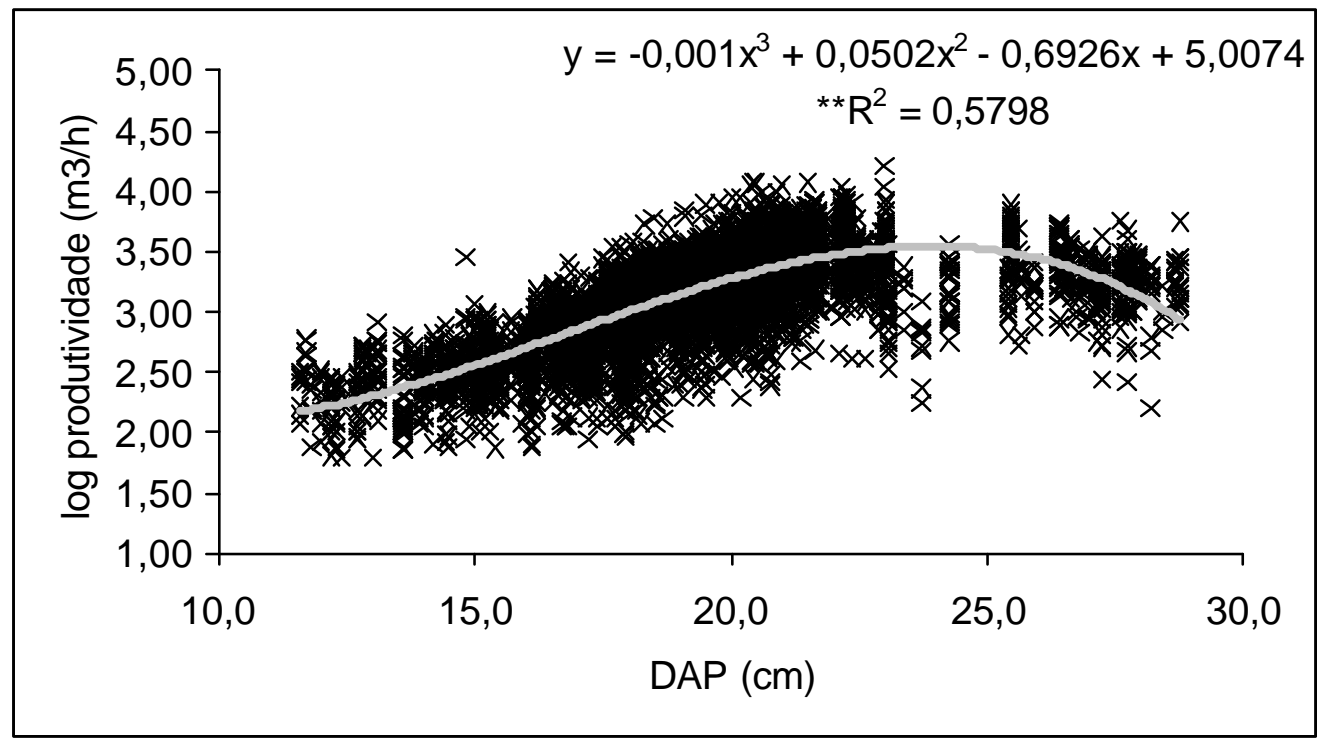

Figura 7 - Gráfico do logaritmo das produtividades dos equipamentos, com descascamento da madeira, em relação ao DAP médio, com a respectiva linha de tendência, equação de regressão e $\mathrm{R}^{2}$.

Nos dois sistemas, os comportamentos dos dados foram bastante semelhantes, com um rápido aumento da produtividade em função do aumento do DAP até aproximadamente $24 \mathrm{~cm}$ notando-se uma forte tendência de queda nas produtividades a partir desse valor. Esse comportamento indica que, em média, os cabeçotes processadores utilizados são mais adequados para trabalhar com árvores até $24 \mathrm{~cm}$ de DAP.

Seria importante que esse tipo de informação fizesse parte das especificações dos cabeçotes processadores, onde geralmente consta apenas o diâmetro máximo de corte, que dificilmente é alcançado em plantios comerciais. 


\subsubsection{Altura média das árvores}

Da mesma forma que o DAP, a altura também possui forte influência sobre a produtividade dos equipamentos de colheita. Observando os resultados nas figuras 8 e 9 , nota-se que não existe diferença entre os dois sistemas. Vale ressaltar, porém, que não existe a tendência de queda da produtividade, mas sim de estabilização a partir de 40m de altura, provavelmente porque o aumento em altura não implica em ultrapassar os limites operacionais dos equipamentos, que estão mais diretamente ligados ao diâmetro.

Esse comportamento sugere que, eventualmente, o melhoramento florestal talvez devesse buscar um ganho maior em altura, que em diâmetro. Conseguindo assim, o aumento da produtividade da floresta mantendo a capacidade de produção dos equipamentos de colheita.

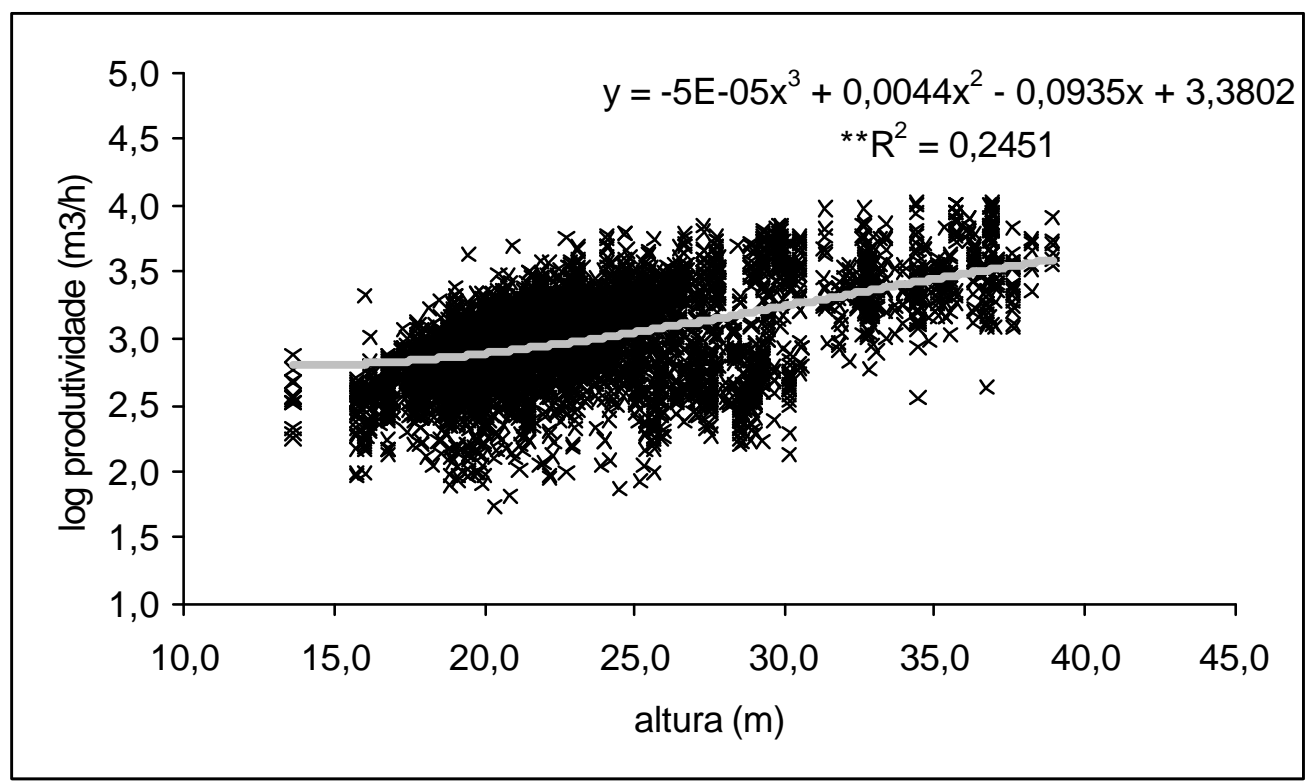

.Figura 8 - Gráfico do logaritmo das produtividades dos equipamentos, sem descascamento da madeira, em relação à altura média, com a respectiva linha de tendência, equação de regressão e $\mathrm{R}^{2}$. 


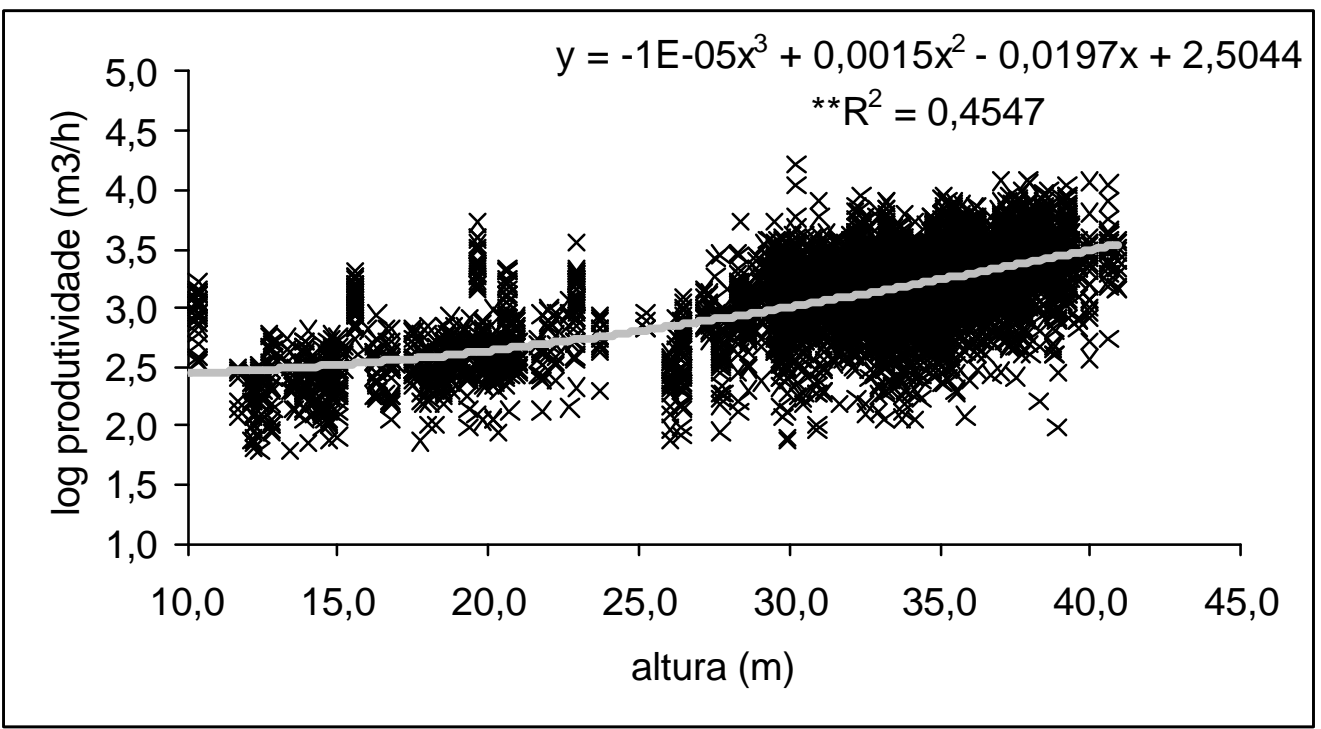

Figura 9 - Gráfico do logaritmo das produtividades dos equipamentos, com descascamento da madeira, em relação à altura média, com a respectiva linha de tendência, equação de regressão e $\mathrm{R}^{2}$.

\subsubsection{Volume por hectare}

O volume de madeira por hectare está fortemente relacionado ao aumento do volume individual das árvores $\left(\mathrm{R}^{2}=0,74\right.$ para madeira com casca e 0,84 para madeira sem casca). Em função disso, é natural que seja encontrada uma influência dessa variável sobre a produtividade dos "harvesters".

Como pode ser visto nas figuras 10 e 11, os comportamentos das curvas de regressão são bastante semelhantes aos verificados nas avaliações dos volumes individuais das árvores (figuras 4 e 5), porém com coeficientes de determinação menores, possivelmente, porque o volume por hectare engloba, além do volume das árvores, a densidade da floresta, o que torna a relação menos direta. 


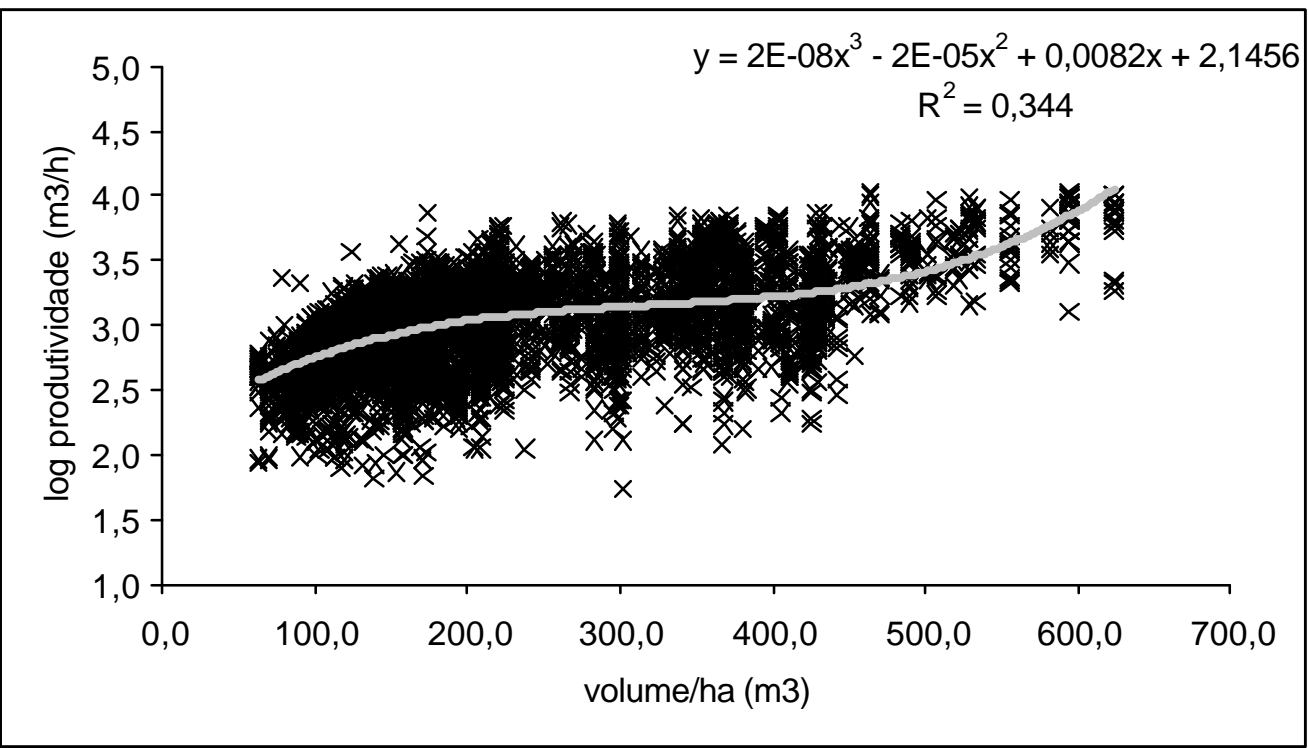

Figura 10 - Gráfico do logaritmo das produtividades dos equipamentos, sem descascamento da madeira, em relação ao volume de madeira por hectare, com a respectiva linha de tendência, equação de regressão e $\mathrm{R}^{2}$.

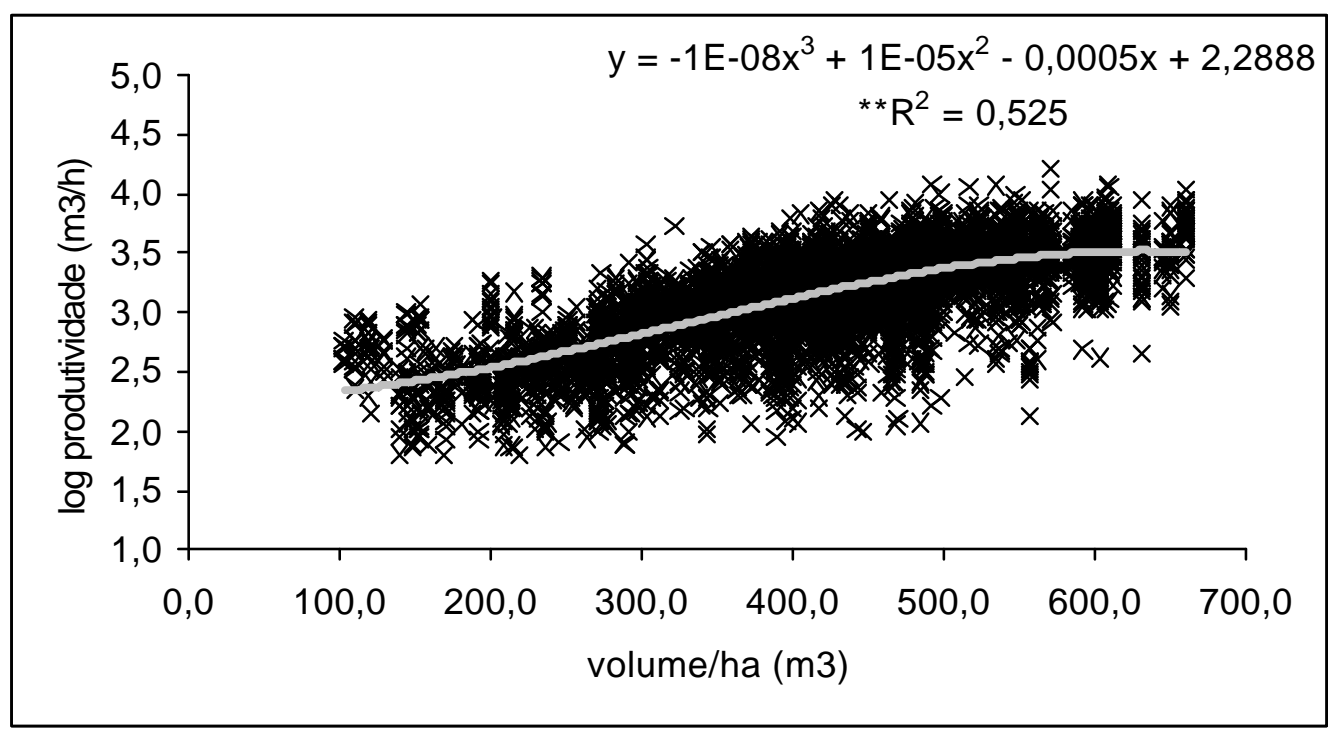

Figura 11 - Gráfico do logaritmo das produtividades dos equipamentos, com descascamento da madeira, em relação ao volume de madeira por hectare, com a respectiva linha de tendência, equação de regressão e $\mathrm{R}^{2}$. 


\subsection{5 Árvores por hectare}

O aumento da densidade da floresta implica diretamente na redução do volume individual das árvores. Como pode ser visto nas figuras 12 e 13, essa redução resulta numa queda considerável na capacidade produtiva dos "harvesters", em função do aumento do número de árvores por hectare, principalmente no sistema com descascamento de madeira.

Essa redução da capacidade de produção dos "harvesters", com o aumento da densidade de plantio, também pode ser atribuída à maior dificuldade de movimentação dos equipamentos e de arranjamento das árvores derrubadas.

Esse tipo de comportamento deve ser levado em conta na ocasião do planejamento do plantio, sendo que, do ponto de vista da produtividade dos equipamentos de colheita, a faixa ideal está entre 800 e 1200 árvores/ha.

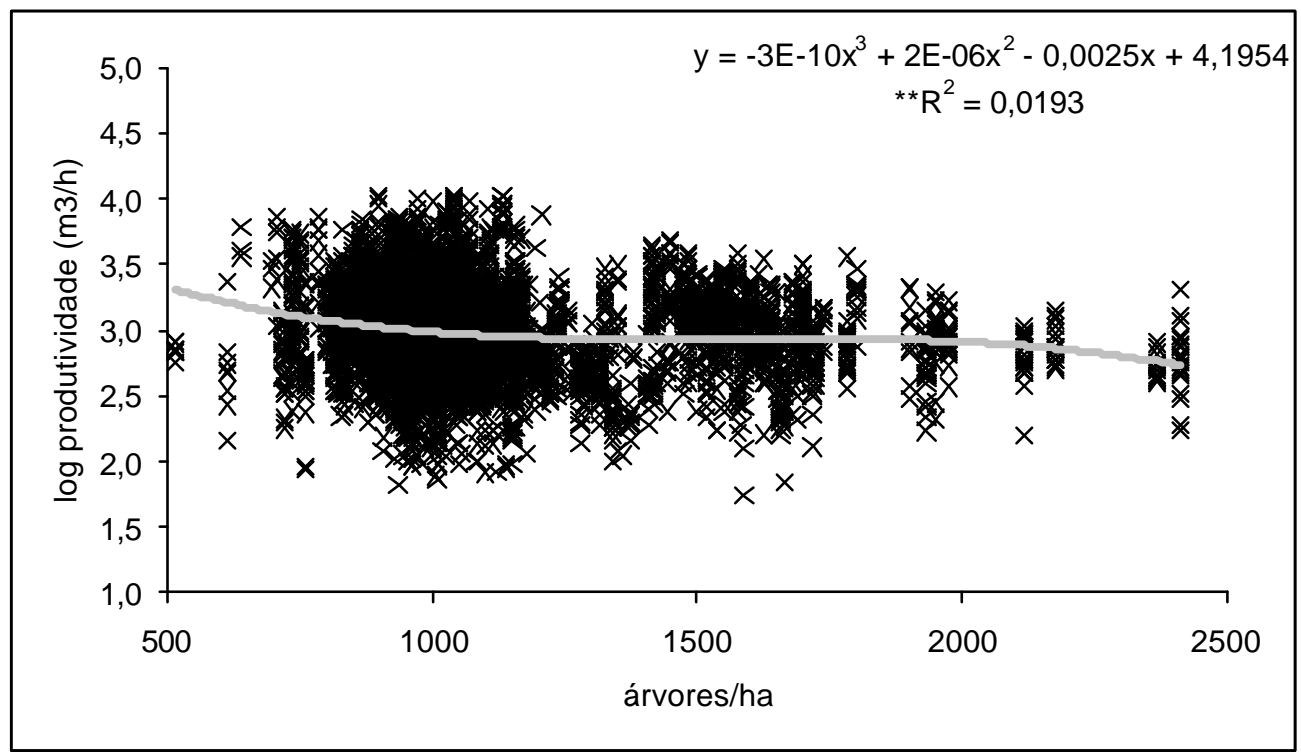

Figura 12 - Gráfico do logaritmo das produtividades dos equipamentos, sem descascamento da madeira, em relação ao número de árvores por hectare, com a respectiva linha de tendência, equação de regressão e $\mathrm{R}^{2}$. 


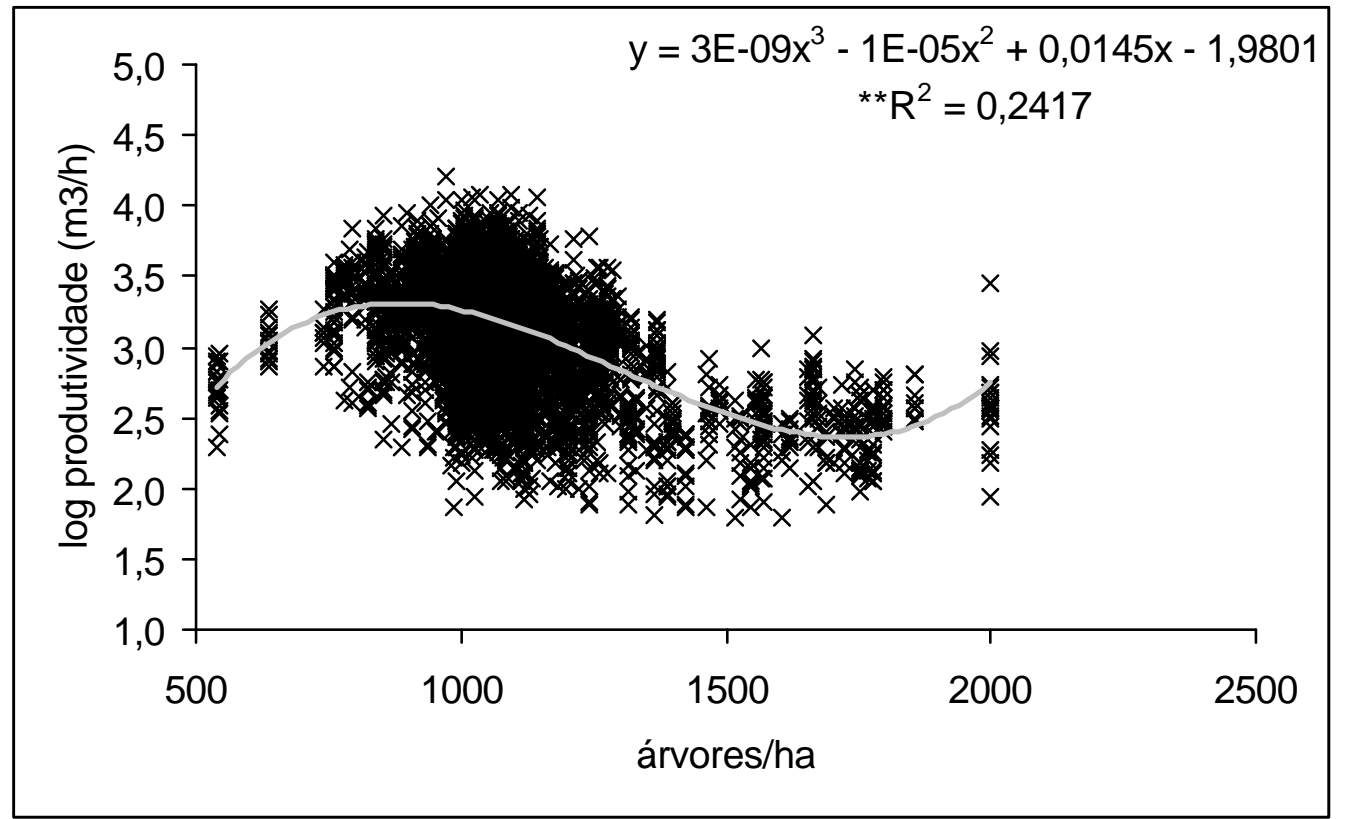

Figura 13 - Gráfico do logaritmo das produtividades dos equipamentos, com descascamento da madeira, em relação ao número de árvores por hectare, com a respectiva linha de tendência, equação de regressão e $\mathrm{R}^{2}$.

\subsubsection{Idade de corte}

Existe uma tendência natural do aumento do volume individual das árvores com o aumento da idade. Em função disso, verificourse um aumento da produtividade dos "harvesters" com o aumento da idade de corte (figuras 14 e 15). Esse aumento é bastante evidente na faixa entre seis e dez anos.

Nota-se uma diferença acentuada entre os sistemas com e sem descascamento, em relação aos comportamentos das curvas, que pode ser atribuída à existência de um conjunto de pontos na faixa de 13 anos com baixa produtividade, no sistema com descascamento da madeira, provavelmente em virtude de algum problema de sítio ou 
material genético específico de um talhão, que resultou em árvores com baixo volume individual.

Chama a atenção o fato de que nos dois sistemas, a idade de 7 anos, que é considerada a idade ideal de corte do eucalipto, esteja ligada às faixas de menor produtividade dos equipamentos de colheita.

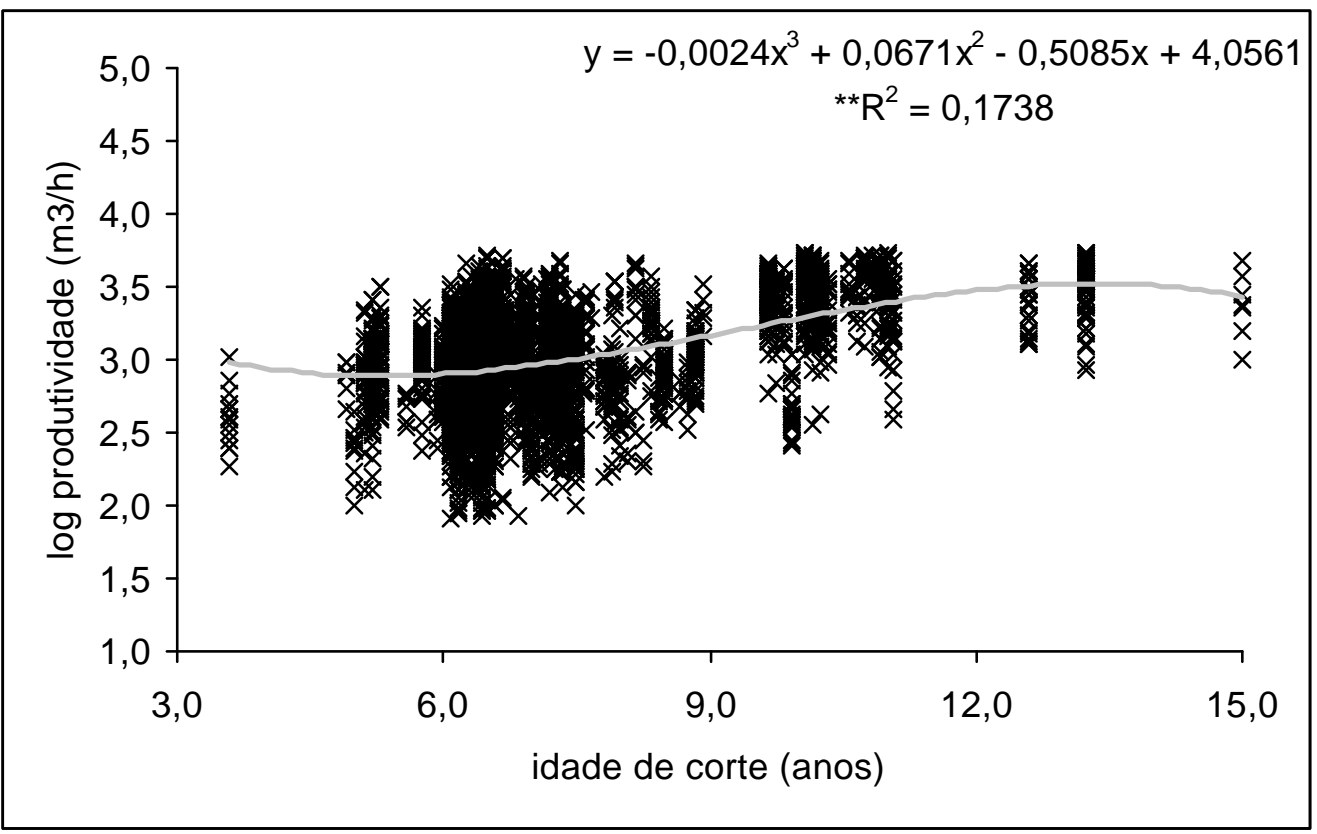

Figura 14 - Gráfico do logaritmo das produtividades dos equipamentos, sem descascamento da madeira, em relação à idade de corte da floresta, com a respectiva linha de tendência, equação de regressão e $\mathrm{R}^{2}$. 


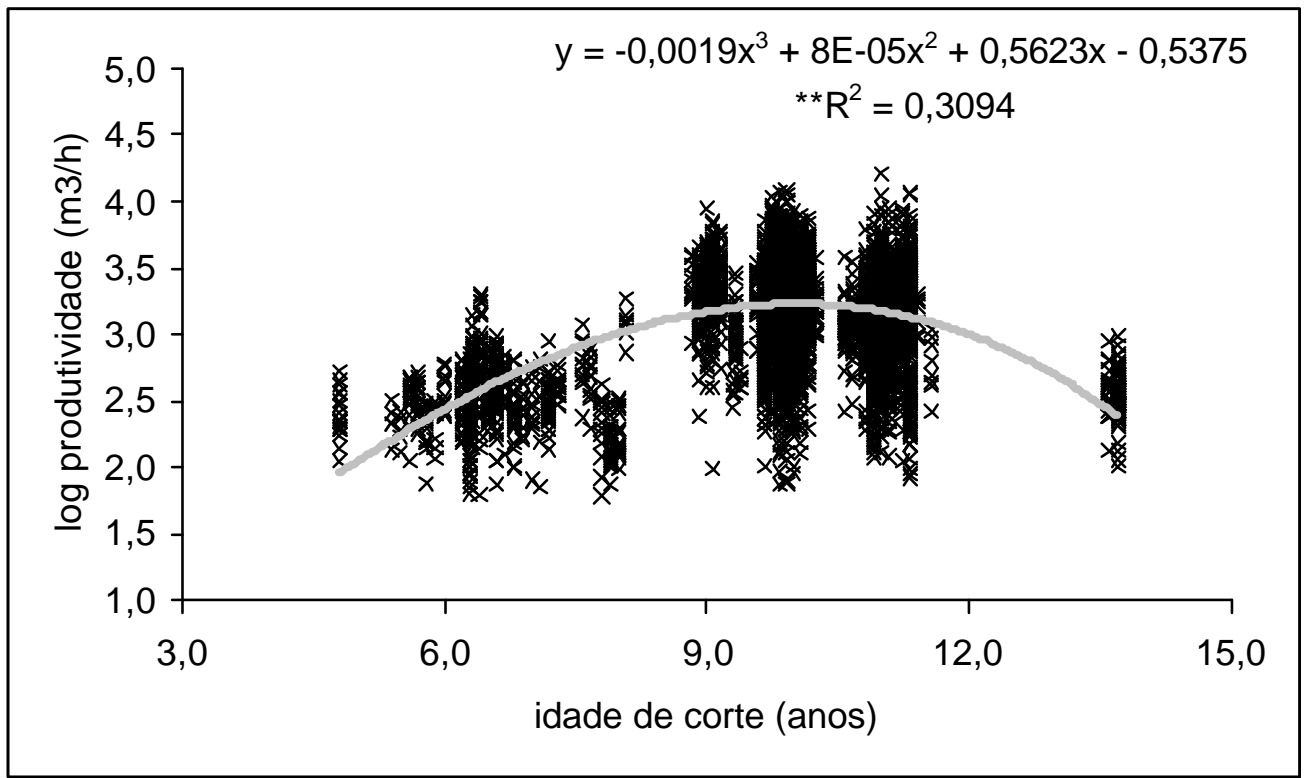

Figura 15 - Gráfico do logaritmo das produtividades dos equipamentos, com descascamento da madeira, em relação à idade de corte da floresta, com a respectiva linha de tendência, equação de regressão e $\mathrm{R}^{2}$.

\subsubsection{Experiência do operador}

Para verificar a influência do tempo de experiência do operador sobre a produtividade do equipamento, o número de horas trabalhadas em "harvesters" por cada operador foi confrontado com as respectivas produtividades.

Verificou-se uma tendência ao aumento de produtividade com o aumento do número de horas, porém com um efeito relativamente pequeno (figura 16). Esse efeito fraco era esperado, pois segundo Parker et al. (1996), o grande aumento de produtividade do operador de "harvester" ocorre nos primeiros 30 dias de trabalho.

Os dados apresentados são referentes apenas aos operadores da Duratex S.A., uma vez que nas outras empresas não foi possível o levantamento dessa informação. 


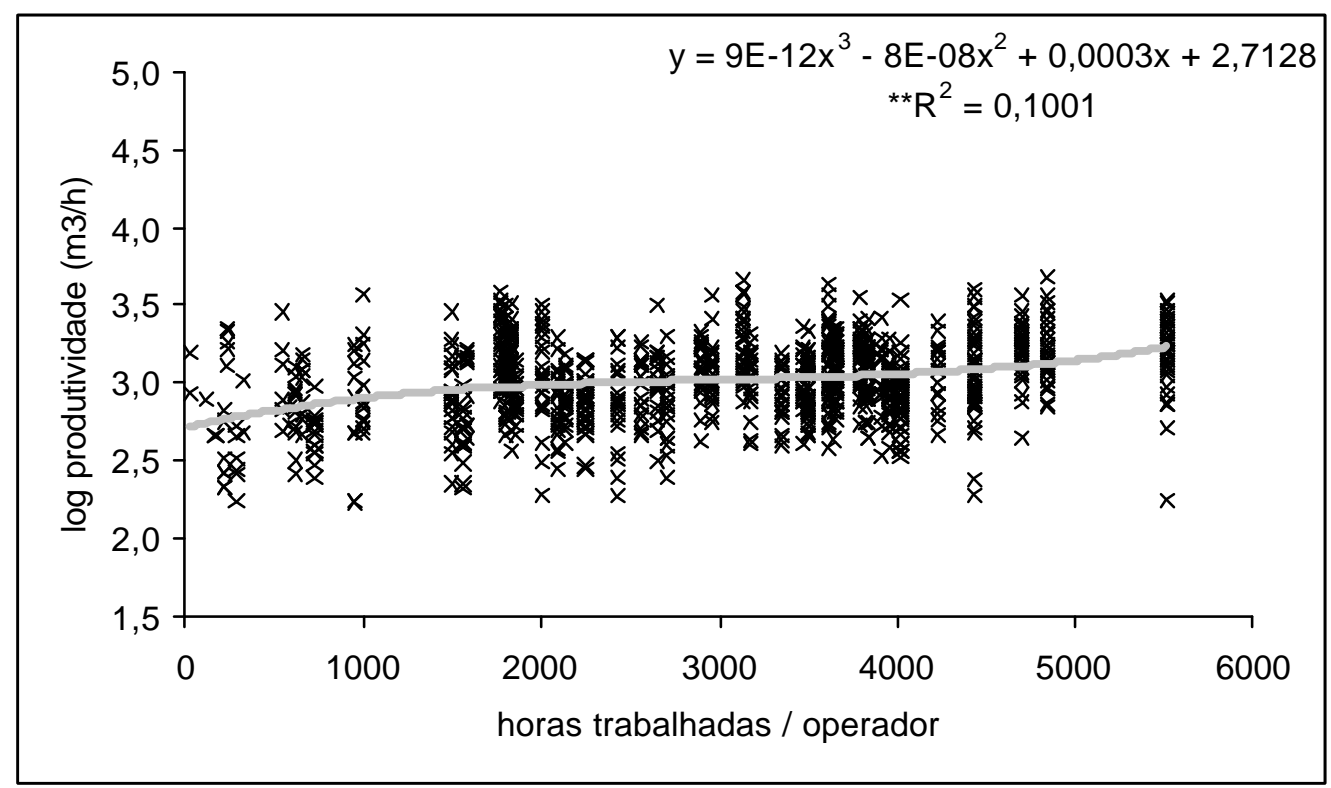

Figura 16 - Gráfico das produtividades dos equipamentos, sem descascamento da madeira, em relação ao tempo de experiência dos operadores em "harvesters", com a respectiva linha de tendência, equação de regressão e $\mathrm{R}^{2}$

\subsubsection{Modelos dos equipamentos}

Com o intuito de se analisar a influência do tipo de equipamento sobre a produtividade alcançada, os equipamentos utilizados foram agrupados de acordo com suas características construtivas, fabricante e modelo da máquina base e tipo de cabeçote processador (tabela1). 
Tabela 1. Grupos de equipamentos analisados com suas principais características construtivas.

\begin{tabular}{ccccc}
\hline Grupo & "Harvester" & Rodado & Cabeçote & Potência (Kw) \\
\hline 1 & Sisu-Valmet 601 & $4 \times 4$ & Valmet 960 & 128 \\
2 & Bell & esteiras & FX 450 & 73,5 \\
3 & Timberjack 608 & esteiras & Risley slingshot & 125 \\
4 & Caterpillar 320 & esteiras & Risley slingshot & 95,5 \\
5 & Sisu-Valmet 601 & 6x6 & Valmet 960 & 128 \\
6 & Caterpillar 320 & esteiras & Valmet 960 & 95,5 \\
7 & Fiat FH 200 & esteiras & Valmet 965 & 105 \\
8 & Volvo EC 201 & Esteiras & Votec W-650 & 107 \\
9 & Timberjack 1270B & 6x6 & Timberjack 762-C & 163 \\
10 & Timberjack 2618 & esteiras & Timberjack 762-C & 153 \\
\hline
\end{tabular}

Para comprovar a existência de diferenças significativas entre os resultados alcançados pelos modelos de equipamentos, foi feita a análise de variância entre os resultados obtidos pelos diferentes grupos, mantendo-se a separação por sistema de trabalho, ou seja, com ou sem descascamento de madeira. Em seguida, foi realizado o "Teste de Tukey" para comparação de médias. Nas tabelas 2 e 3 estão plotados os resultados do sistema sem descascamento de madeira, e nas tabelas 4 e 5 , os do sistema com descascamento de madeira.

O grupo 2 foi retirado da análise por ser composto apenas por uma máquina antiga e que contava apenas com oito valores anotados durante todo o ano de 2000. 
Tabela 2. Análise de variância entre os diferentes modelos de equipamentos que operaram no sistema sem descascamento da madeira.

\begin{tabular}{cccccc}
\hline & GL & SQ & QM & F & Valor - p \\
\hline Modelo & 6 & 13661,83 & 2276,97 & 49,84 & 0,0001 \\
Resíduo & 7078 & 323362,56 & 45,69 & & \\
Total & 7084 & 337024,38 & & & \\
\hline
\end{tabular}

Tabela 3. Análise comparativa das médias de produtividade dos grupos de equipamentos que operaram sem o descascamento de madeira.

\begin{tabular}{ccc}
\hline Modelo & Média & Número de amostras \\
\hline 8 & $24,15 \mathrm{a}$ & 909 \\
4 & $21,06 \mathrm{~b}$ & 158 \\
7 & $20,87 \mathrm{~b}$ & 1210 \\
5 & $20,46 \mathrm{bc}$ & 207 \\
6 & $20,25 \mathrm{bc}$ & 4266 \\
3 & $18,78 \mathrm{~cd}$ & 252 \\
1 & $17,17 \mathrm{~d}$ & 83 \\
\hline
\end{tabular}

Médias seguidas da mesma letra não diferem entre si pelo teste de "tukey" com $5 \%$ de probabilidade.

Observando-se os resultados obtidos nota-se que a maioria dos modelos de equipamentos analisados apresentam valores médios de capacidade produtiva bastante próximos. O modelo oito que se sobressai em relação aos demais, tem um excelente desempenho em árvores de maior volume individual, o que contribuiu para o aumento da sua média de produtividade, conforme será apresentado oportunamente.

Destaca-se também o desempenho do modelo quatro, com boa capacidade produtiva, uma vez que tratam-se de máquinas equipadas com cabeçote "slingshot", que em teoria, deveriam apresentar produtividades inferiores. 
Tabela 4. Análise de variância entre os diferentes modelos de equipamentos que operaram no sistema com descascamento da madeira.

\begin{tabular}{cccccc}
\hline & GL & SQ & QM & F & Valor $-\mathrm{p}$ \\
\hline Modelo & 3 & 115529,59 & 38509,86 & 748,57 & 0,0001 \\
Resíduo & 7392 & 380280,02 & 51,44 & & \\
Total & 7395 & 495809,61 & & & \\
\hline
\end{tabular}

Tabela 5. Análise comparativa das médias de produtividade dos grupos de equipamentos que operaram descascando a medira no campo.

\begin{tabular}{ccc}
\hline Modelo & Média & Número de amostras \\
\hline 8 & $25,78 \mathrm{a}$ & 6654 \\
6 & $19,16 \mathrm{~b}$ & 55 \\
10 & $13,30 \mathrm{c}$ & 149 \\
9 & $11,97 \mathrm{c}$ & 538 \\
\hline
\end{tabular}

Médias seguidas da mesma letra não diferem entre si pelo teste de "tukey" com 5\% de probabilidade.

Novamente, o modelo oito conseguiu uma média de produtividade bastante superior aos demais, inclusive, superior à sua média no sistema sem descascamento de madeira, provavelmente em função de terem sido colhidas mais árvores com maior volume individual nesse sistema (figuras 4 e 5).

\subsubsection{Combinações máquina / operador}

Por razões operacionais das empresas, em alguns talhões que foram analisados ocorreram até 30 combinações diferentes de máquina e operador. Em alguns casos um operador trabalhou por 30 minutos ou uma hora em um equipamento em um determinado talhão, enquanto que em outros talhões ocorreram apenas três combinações, 
com os operadores trabalhando dezenas de horas em um mesmo equipamento. Seria de se esperar que onde houvesse menor intercâmbio de máquinas e operadores, fosse alcançada uma maior produtividade dos equipamentos.

Para testar essa hipótese, foi feita uma regressão simples entre o número de combinações máquina/operador e a produtividade alcançada, cujo resultado está representado na figura 17, sendo não significativo.

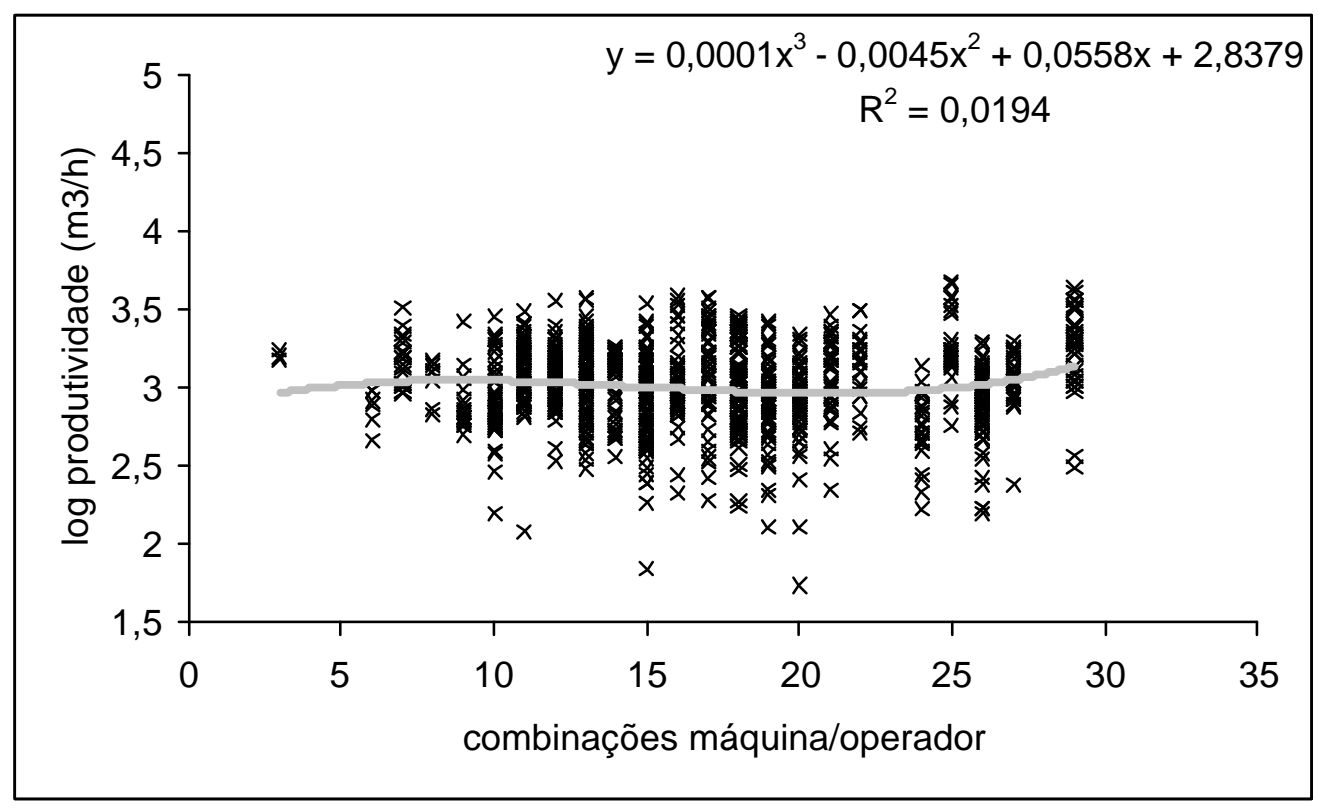

Figura 17 - Gráfico do logaritmo das produtividades dos equipamentos em relação ao número de combinações máquina/operador, com a respectiva linha de tendência e $\mathrm{R}^{2}$. 


\subsubsection{Pluviosidade no mês da colheita}

A presença de um teor elevado de umidade no solo na ocasião da colheita, teoricamente, deve dificultar o deslocamento dos equipamentos de colheita, interferindo em sua produtividade, em especial nos terrenos com maior declividade.

Com o objetivo de verificar a influência do teor de umidade no solo sobre a produtividade dos "harvesters", foram confrontados os índices pluviométricos dos meses em que foram realizadas as operações de colheita e as produtividades alcançadas.

Durante a análise dos dados notoutse a existência de interação da topografia do terreno com a umidade no solo. Em função disso, foram construídos dois gráficos, um apenas com dados da VCP, Votorantim Celulose e Papel, que opera com "harvesters" em terrenos inclinados (figura 18), e outro com dados da Aracruz, que opera apenas em terrenos planos (figura 19), ambos com descascamento de madeira feito pelos "harvesters".

Como pode ser visto nos gráficos das figuras 18 e 19 a presença de umidade no solo afeta de forma significativa a produtividade dos "harvesters" apenas em terrenos com maior declividade, sendo que em terrenos planos o modelo não foi significativo. 


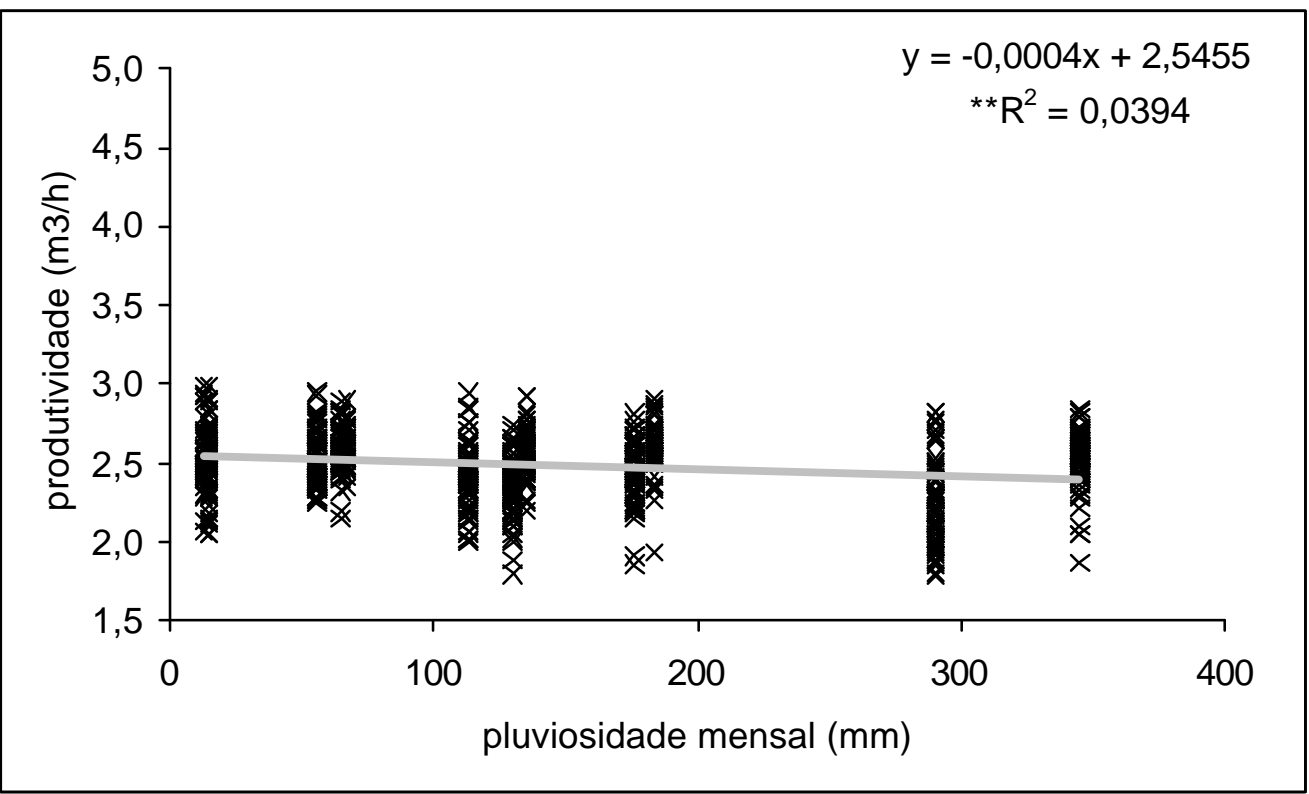

Figura 18 - Gráfico do logaritmo da produtividade em relação aos índices pluviométricos mensais na ocasião da colheita em terreno inclinado (VCP).

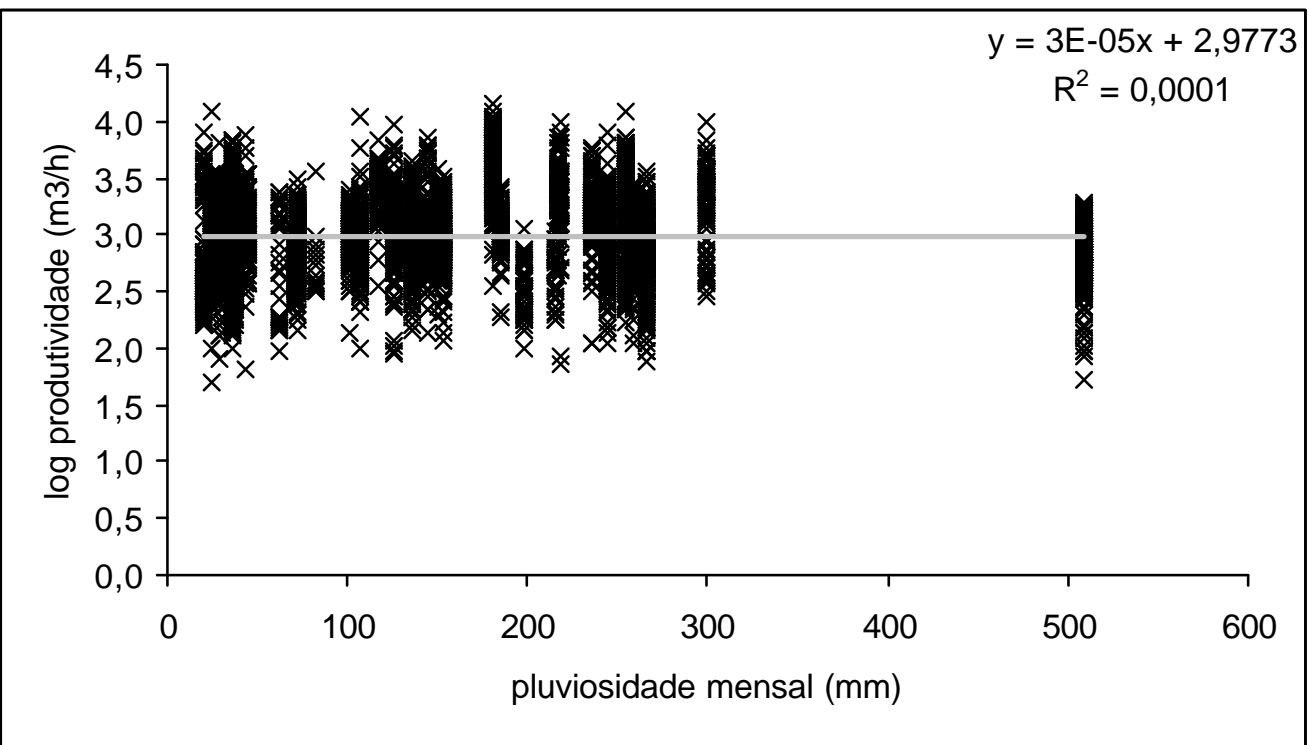

Figura 19 - Gráfico do logaritmo da produtividade em relação aos índices pluviométricos mensais na ocasião da colheita em terreno plano (Aracruz). 


\subsection{Regressões lineares múltiplas}

Com o objetivo de obter um modelo que se ajustasse melhor aos dados, e dessa forma fosse mais preciso na predição das produtividades dos "harvesters", foram feitas regressões lineares múltiplas para os dois sistemas de operação.

\subsubsection{Sistema sem descascamento de madeira feito pelo "harvester"}

Inicialmente foi feita uma regressão linear múltipla com todas as variáveis disponíveis em todos os bancos de dados e que se mostraram significativas nas regressões simples. Os modelos de equipamentos foram incluídos na forma de variável classificatória "Dunmy" (Tabela 6).

Tabela 6. Resultado da regressão linear múltipla, realizada com todas as variáveis, para o sistema sem descascamento de madeira.

\begin{tabular}{|c|c|c|c|c|}
\hline & Coeficientes & Erro padrão & Stat $t$ & valor- $P$ \\
\hline Interseção & 2,25589 & 0,04139 & 54,49911 & 0,00000 \\
\hline $\mathrm{DAP}(\mathrm{cm})$ & $-0,00185$ & 0,00198 & $-0,93780$ & 0,34838 \\
\hline Volume/árvore $\left(\mathrm{m}^{3}\right)$ & 2,88754 & 0,06889 & 41,91507 & 0,00000 \\
\hline Volume/hectare $\left(\mathrm{m}^{3}\right)$ & 0,00150 & 0,00016 & 9,24975 & 0,00000 \\
\hline Altura (m) & 0,01297 & 0,00159 & 8,16742 & 0,00000 \\
\hline Árvores/ha & 0,00000 & 0,00001 & $-0,30844$ & 0,75776 \\
\hline Idade de corte (anos) & $-0,03426$ & 0,00293 & $-11,69209$ & 0,00000 \\
\hline EQ 3* & 0,05644 & 0,02254 & 2,50429 & 0,01229 \\
\hline EQ 4 & 0,09568 & 0,02328 & 4,10985 & 0,00004 \\
\hline EQ 5 & 0,09015 & 0,02221 & 4,05877 & 0,00005 \\
\hline EQ 6 & 0,24577 & 0,01997 & 12,30846 & 0,00000 \\
\hline EQ 7 & 0,15778 & 0,02053 & 7,68461 & 0,00000 \\
\hline EQ 8 & $-0,12630$ & 0,02237 & $-5,64541$ & 0,00000 \\
\hline
\end{tabular}

Significativo com $5 \%$ de probabilidade

$\mathrm{R}^{2}=0,7701 \quad$ Erro padrão da estimativa $=0,1968$

*Os modelos representados pela sigla EQ estão descritos na página 34 
Em seguida, foi feita nova regressão sem as variáveis que não apresentaram valor-P significativo e sem a variável "idade de corte", que apresentou coeficiente negativo, quando o natural seria que o coeficiente fosse positivo. Esse tipo de ocorrência sugere a existência de problemas de multi-colinearidade, ou seja, a inclusão de duas variáveis estritamente relacionadas na mesma regressão (Tabela 7).

Tabela 7. Resultado da regressão linear múltipla, realizada sem as variáveis DAP, idade de corte e árvores por hectare, para o sistema sem descascamento de madeira.

\begin{tabular}{lcccc}
\hline & Coeficientes & Erro padrão & Stat t & valor-P \\
\hline Interseção & 2,04738 & 0,03033 & 67,51358 & 0,00000 \\
Volume/árvore $\left(\mathrm{m}^{3}\right)$ & 2,23711 & 0,08009 & 27,93099 & 0,00000 \\
Volume/hectare $\left(\mathrm{m}^{3}\right)$ & 0,00026 & 0,00007 & 3,96597 & 0,00007 \\
Altura (m) & 0,01270 & 0,00147 & 8,62971 & 0,00000 \\
EQ 3 & 0,08399 & 0,02269 & 3,70117 & 0,00022 \\
EQ 4 & 0,08829 & 0,02354 & 3,75114 & 0,00018 \\
EQ 5 & 0,06746 & 0,02237 & 3,01576 & 0,00257 \\
EQ 6 & 0,25819 & 0,01987 & 12,99195 & 0,00000 \\
EQ 7 & 0,18931 & 0,02060 & 9,19075 & 0,00000 \\
EQ 8 & $-0,13983$ & 0,02212 & $-6,32284$ & 0,00000 \\
\hline Sign
\end{tabular}

Significativo com $5 \%$ de probabilidade $\mathrm{R}^{2}=0,7655$

Erro padrão da estimativa $=0,1986$

Os resíduos foram plotados no gráfico da figura 20. Como pode ser visto, o modelo tende a superestimar a produtividade prevista, principalmente quando a previsão é de valores mais altos. 


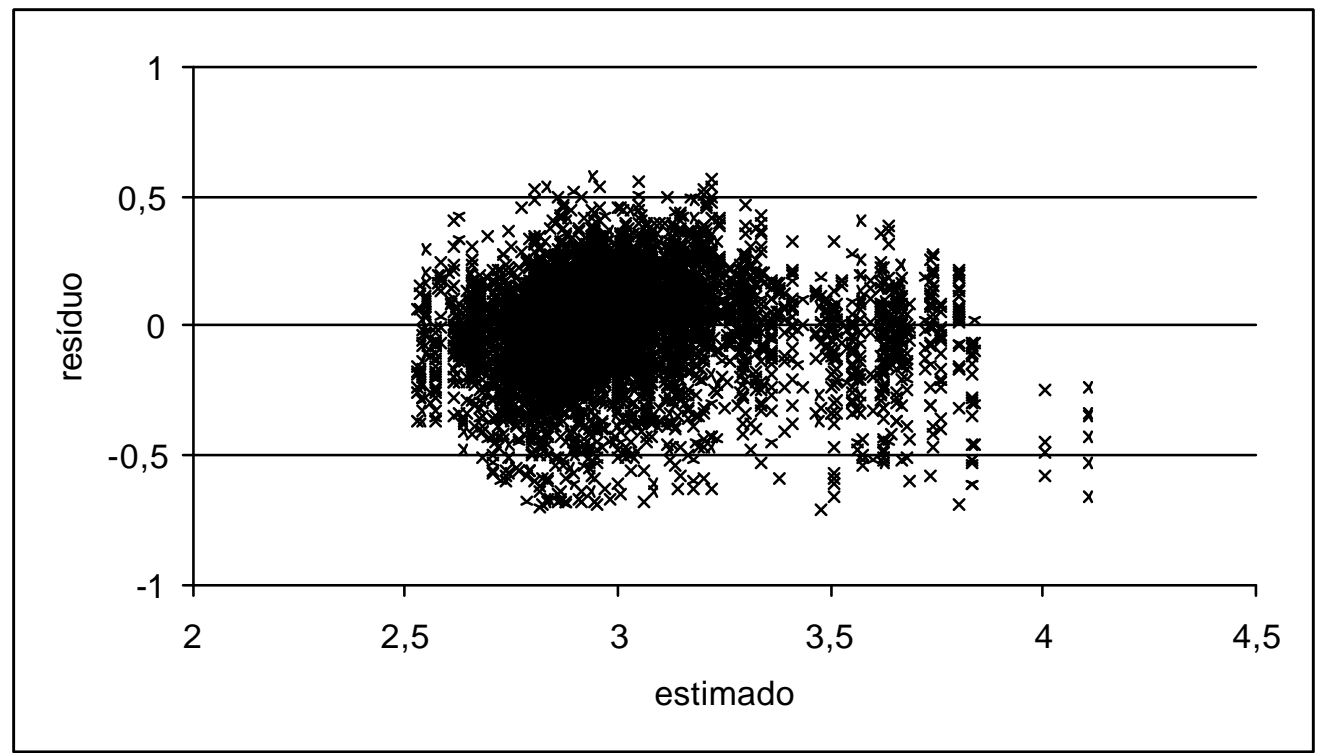

Figura 20 - Gráfico dos resíduos em relação ao valor estimado pela regressão múltipla para o logaritmo da produtividade $\left(\mathrm{m}^{3} / \mathrm{h}\right)$.

Analisando-se os coeficientes apresentados na tabela 6, destaca-se o fato do equipamento oito, que, segundo o "Teste de Tukey", apresenta a melhor média de produtividade, apresentar coeficiente negativo. Na tentativa de buscar uma explicação, gerou-se um gráfico com as produtividades alcançadas por alguns dos modelos avaliados em relação ao volume individual das árvores (Figura 21). 


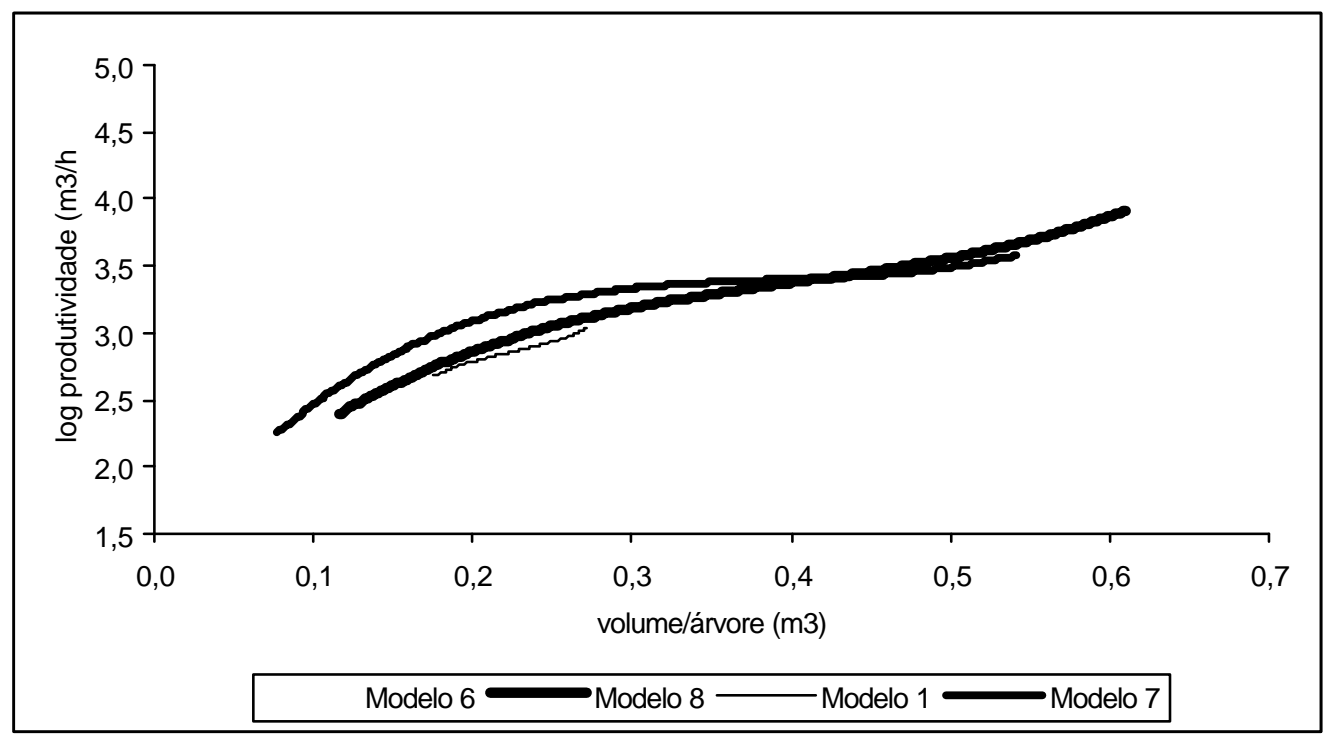

Figura 21 - Gráfico dos logaritmos das produtividades alcançadas por tipo de equipamento em função do volume individual das árvores.

Como pode ser visto, o modelo oito apesar de apresentar a melhor média geral de produtividade, quando opera com árvores de até $0,4 \mathrm{~m}^{3}$ apresenta produtividade inferior aos modelos seis e sete e bastante próxima do modelo um, que apresenta a média geral mais baixa, justificando dessa forma o coeficiente negativo da regressão múltipla.

Dessa forma o modelo final de regressão para o sistema sem descascamento de madeira pelo "harvester" fica com o seguinte formato:

Prod. $\left(\mathrm{m}^{3} / \mathrm{h}\right)=e^{\left(\begin{array}{l}2,04738+E Q+2,2371 * \text { volumel árvore }\left(\mathrm{m}^{3}\right)+ \\ 0,0127 * \text { altura }(m)+0,00026 * \text { volume } / \text { hectare }\left(m^{3}\right)\end{array}\right)}$

Onde $\mathrm{EQ}=$ coeficiente para cada tipo de equipamento utilizado conforme tabela 7 e para EQ1: coeficiente $=0$.

$\mathrm{R}^{2}=0,7655$

Erro padrão da estimativa $=0,1986$ 


\subsubsection{Sistema com descas camento de madeira feito pelo "harvester"}

Foi utilizada a mesma metodologia do sistema anterior, ou seja, uma regressão linear múltipla com todas as variáveis que estavam disponíveis em todos os bancos de dados e se mostraram significativas nas regressões simples. Os modelos de equipamentos foram incluídos na forma de variável classificatória “Dunmy” (Tabela 8).

Tabela 8. Resultado da regressão linear múltipla, realizada com todas as variáveis, para o sistema sem descascamento de madeira.

\begin{tabular}{lcccc}
\hline & Coeficientes & Erro padrão & Stat t & valor-P \\
\hline Interseção & 2,16473 & 0,05676 & 38,13514 & 0,00000 \\
Volume/árvore $\left(\mathrm{m}^{3}\right)$ & 1,81768 & 0,15208 & 11,95251 & 0,00000 \\
DAP $(\mathrm{cm})$ & $-0,00218$ & 0,00158 & $-1,37633$ & 0,16876 \\
Altura $(\mathrm{m})$ & 0,00422 & 0,00084 & 5,01596 & 0,00000 \\
Volume/hectare $\left(\mathrm{m}^{3}\right)$ & 0,00041 & 0,00014 & 2,87137 & 0,00410 \\
Idade de corte $(\mathrm{anos})$ & $-0,02983$ & 0,00280 & $-10,64884$ & 0,00000 \\
Árvore/ha & 0,00001 & 0,00004 & 0,19675 & 0,84403 \\
EQ 10 & 0,08971 & 0,02092 & 4,28725 & 0,00002 \\
EQ 6 & 0,44478 & 0,03373 & 13,18660 & 0,00000 \\
EQ 8 & 0,30985 & 0,01755 & 17,65225 & 0,00000 \\
\hline
\end{tabular}

Significativo com $5 \%$ de probabilidade

$\mathrm{R}^{2}=0,7950$

Erro padrão da estimativa $=0,2243$

Os modelos representados pela sigla EQ estão descritos na página 34

Em seguida foi feita nova regressão sem as variáveis que não apresentaram valor-P significativo e sem a variável "idade de corte" que apresentou œeficiente negativo quando o natural seria que o coeficiente fosse positivo, novamente indicando problemas de multi-colinearidade (Tabela 9). A distribuição dos resíduos pode ser vista no gráfico da Figura 22. 
Tabela 9. Resultado da regressão linear múltipla, realizada com todas as variáveis, para o sistema com descascamento de madeira.

\begin{tabular}{lcccc}
\hline & Coeficientes & Erro padrão & Stat t & valor-P \\
\hline Interseção & 1,96203 & 0,01590 & 123,36934 & 0,00000 \\
Volume/árvore $\left(\mathrm{m}^{3}\right)$ & 1,95317 & 0,06794 & 28,75014 & 0,00000 \\
Altura $(\mathrm{m})$ & 0,00294 & 0,00084 & 3,51068 & 0,00045 \\
Volume/hectare $\left(\mathrm{m}^{3}\right)$ & 0,00024 & 0,00006 & 3,69289 & 0,00022 \\
EQ 10* & 0,06623 & 0,02096 & 3,15920 & 0,00159 \\
EQ 6 & 0,44698 & 0,03319 & 13,46659 & 0,00000 \\
EQ 8 & 0,23473 & 0,01514 & 15,50671 & 0,00000 \\
\hline
\end{tabular}

Significativo com $5 \%$ de probabilidade

$R^{2}=0,7913$

Erro padrão da estimativa $=0,2261$

Os modelos representados pela sigla EQ estão descritos na página 34

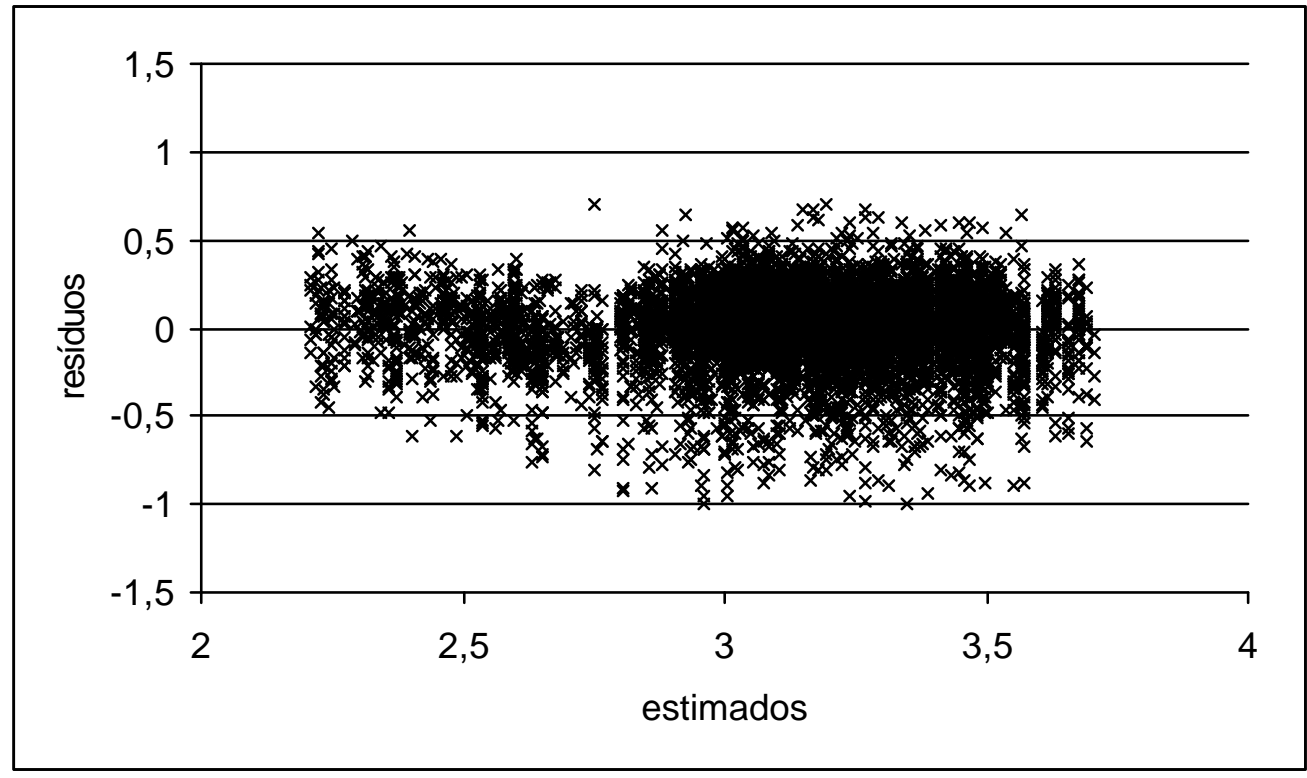

Figura 22 - Gráfico dos valores estimados pela regressão múltipla, contra os resíduos. 
Da mesma forma que o modelo anterior, o modelo do sistema com descascamento de madeira, tende a superestimar a produtividade prevista.

Analisando o erro padrão da estimativa dos dois sistemas, verificamos que em função da escala adotada (logarítmica), o erro possível para o valor estimado aumenta rapidamente com o aumento do valor estimado. Ou seja, se o valor estimado for 2,5 log produtividade, um erro de 0,22 equivale a $3 \mathrm{~m}^{3} / \mathrm{h}$ de erro, já se o mesmo erro ocorrer para uma produtividade prevista de 4,0 log da produtividade, equivale a $13,4 \mathrm{~m}^{3} / \mathrm{h}$.

Portanto, pode-se afirmar que os modelos produzidos perdem eficiência com o aumento da produtividade prevista, sendo que até 3,0 log da produtividade o erro padrão da estimativa representa um erro de mais ou menos $5 \mathrm{~m}^{3} / \mathrm{h}$, o que é considerado um valor aceitável.

Dessa forma, o modelo final para o sistema com descascamento de madeira feito pelo "harvester" ficou com a seguinte forma:

Prod. $\left(\mathrm{m}^{3} / \mathrm{h}\right)=e^{\left(\begin{array}{c}1,96203+E Q+\text { Volume / árvore }\left(\mathrm{m}^{3}\right) * 1,9532+ \\ \text { Altura }(m) * 0,00294+\text { Volume } / \mathrm{ha}\left(\mathrm{m}^{3}\right) * 0,00024\end{array}\right)}$

Onde EQ = coeficiente para o tipo de equipamento utilizado, conforme tabela 8 e para EQ 9: coeficiente $=0$.

$\mathrm{R}^{2}=0,7913$

Erro padrão da estimativa $=0,2261$ 
Segundo Gingras (1988) e Salmeron (1997), a declividade do terreno é uma variável que tem influência sobre a capacidade produtiva dos equipamentos de colheita florestal.

Além disso, o fato da umidade no solo interferir apenas sobre a produtividade dos equipamentos que, em geral, operam em terrenos declivosos (item 4.1.10), reforça ainda mais essa idéia. Entretanto, não foi possível a aquisição de dados que permitissem essa análise, uma vez que a única empresa que possuí esse tipo de equipamento operando em terreno inclinado, não dispõe de valores médios de declividade dos talhões, em função de que dentro de um mesmo talhão essa declividade pode variar de zero a 80\%. Sem dúvida, a inclusão da declividade do terreno nos modelos teria colaborado para o aumento da sua precisão.

Apesar disso, a utilização dos modelos obtidos através das regressões múltiplas é recomendável para a obtenção de estimativas mais exatas, em condições de trabalho que se assemelhem às abordadas no presente trabalho. A utilização dos modelos gerados pelos volumes individuais das árvores é recomendável, em situações onde não é exigida grande precisão ou quando não estiverem disponíveis todos os dados necessários para a utilização dos modelos múltiplos. 


\section{CONCLUSÕES}

Através dos modelos de regressão simples comprovoutse a hipótese inicial do trabalho, com o volume médio das árvores sendo a variável que melhor explicou, isoladamente, as produtividades alcançadas pelos "harvesters". As outras variáveis de destaque foram DAP médio, altura média e volume por hectare. O volume médio por árvore representou cerca de 55\%, em nédia, da variação da capacidade produtiva da "harvester".

Para a obtenção de modelos mais precisos foi necessária a utilização de regressões lineares múltiplas com a inclusão das variáveis: volume por árvore, altura média, volume por hectare e tipo de equipamento utilizado. Neste caso, as variáveis consideradas em conjunto representam aproximadamente $80 \%$ da capacidade produtiva da máquina.

A utilização dos modelos obtidos neste trabalho em outras situações deve ser encarada com ressalvas, considerando-se as particularidades de cada empresa. Neste caso, recomenda-se a elaboração dos bancos de dados incluindo informações mais aprimoradas sobre a capacidade produtiva dos "harvesters" e uma maior precisão dos valores das possíveis variáveis de influência. 


\section{REFERÊNCIAS BIBLIOGRÁFICAS}

AMABILINI, V.D. Utilização do Harvester na exploração florestal. In: SIMPÓSIO BRASILEIRO SOBRE EXPLORAÇÃO E TRANSPORTE FLORESTAL, 1., Belo Horizonte, 1991. Anais. Belo Horizonte, s.., 1991. p. 349-364.

BULLEY, B. Effect of tree size and stand density on harvester and forwarder productivity in commercial thinning. FERIC Technical Note, n. 292, p. 1-8, jul. 1999.

ELIASSON, L. Simulation of thinning with a single-grip harvester. Forest Science, v.45, n.1, p. 26-34, 1999.

EQUIPE TÉCNICA DA DURATEX a . Utilização do "timber-hauler" no transporte de madeira a curta distância. In: SIMPÓSIO BRASILEIRO SOBRE COLHEITA E TRANSPORTE FLORESTAL, 4., Campinas, 1999. Anais. Viçosa: SIF,UFV, 1999. p. 1-13.

EQUIPE TÉCNICA DA DURATEX b. Colheita de madeira em florestas com baixo volume por árvore. In: SIMPÓSIO BRASILEIRO SOBRE COLHEITA E TRANSPORTE FLORESTAL, 4., Campinas, 1999. Anais. Viçosa, SIF,UFV, 1999. p. 54-72.

EWING, R.H.; LIRETTE, J. Commercial thinning in red pine using a Valmet 544H harvester. FERIC Field Note: Partial Cutting, n. 8, p. 1-2, 1995. 
EWING, R.H.; LIRETTE, J. Commercial thinning on difficult terrain with the Valmet 901C single-grip harvester. FERIC Field Note: Partial Cutting, n. 28, p. 1-2, 1999.

FREITAS, M.; ANTIQUEIRA, A.C. Sistema mecanizado de colheita florestal na Champion Papel e Celulose Ltda. In: CONGRESSO FLORESTAL PANAMERICANO, CONGRESSO FLORESTAL BRASILEIRO, 7., Curitiba, 1993. Anais. Curitiba: SBS,SBEF, 1993. v.2, p.686-687.

GINGRAS, J.F. Mechanized tree-length harvesting using a Keto 150 harvester head. FERIC Field Note: Felling, n. 11, p. 1-2, 1992.

GINGRAS, J.F. The effect of site and stand factors on feller-buncher performance. FERIC Technical Report , n. 84, p. 1-18, nov. 1998.

GODIN, A.E. A comparision of harvesters for harvesting winter-broken jack pine. FERIC Field Note: Felling, n. 27, p. 1-2, 1996.

HOLTZSCHER, M.A.; LANFORD, B.L Tree diameter effects on cost and productivity of cut-to-lenght systems. Forest Products Journal, v. 47, n. 3, p. 25-30, 1997.

HUNT, J.A. Initial thinning trials with the Valmet Woodstar 546 harvester and forwarder. FERIC Field Note: Silviculture, n. 47, p. 1-2, 1992.

HUYLER, N.K.; LEDOUX, C.B. Performance of a cut-to-length harvester in a single-tree and group-selection cut. Washington: USDA, 1999. 6p. (Research Paper, 711)

IWAOKA, M.; ARUGA, K.; SAKURAI, R.; CHO, K.H.; SAKAY, H.; KOBAYASHI, H. Performance of small harvester head in a thinning operation. Journal of Forest Research, v. 4, p. 195-200, 1999.

MCCONCHIE, M.; EVANSON, T. "LIRO Mechanization Research Review” (LMR) LIRO Report, 54 p., 1996. 
MEEK, P. A cut-to-length commercial thinning system using two single-grip harvesters. FERIC Field Note: Partial Cutting, n. 29, p. 1-2, 1999.

MITCHELL, J.L. Valmet Woodstar 546 harvester and forwarder: Short-term evaluation. FERIC Field Note: Processing, n. 42, p. 1-2, 1995.

PLAMONDON, J.A. Tree-length at the stump with the 4500 Ultimate harvester head. FERIC Field Note: Felling, n. 20, p. 1-2, 1993.

PARKER, R.; KIRK, P.; SULLMAN, M. Learning curves of mechanised harvester and forwarder operators. LIRO Report, v. 21, n. 29, p. 1-6, 1996.

PHILLIPS, E.J. Comparison of conventional and mechanical harvesting for the Prince Albert Model Forest. FERIC Special Report, n. 121, p. 1-17, April 1997.

RICHARDSON, R.; GINGRAS, J.F. Shelterwood cutting and commercial thinning of softwwod stands with the Valmet 701 harvester. FERIC Field Note: Partial Cutting, n. 5, p. 1-2, 1995.

RICHARDSON, R.; MAKKONEN, I. The performance of cut-to-lenght systems in Eastern Canada. FERIC Technical Report, n. 109, p. 1-16, Nov. 1994.

SALES, F. O setor florestal avança para a mecanização. Silvicultura, v.6, n.19, p.2030, 1981.

SALMERON, A.; RIBEIRO, R.S. Colheita mecanizada de eucaliptos em regiões acidentadas. In: SEMINÁRIO DE ATUALIZAÇÃO SOBRE SISTEMAS DE COLHEITA E TRANSPORTE FlORESTAL, 10., 1997, Curitiba. 1997. Anais. Curitiba: UFPr,FUPEF, 1997. p. 165-181.

SANTOS, S.L.M.; MACHADO, C.C. Análise técnico-econômica da processamento de madeira de eucalipto em áreas planas, utilizando o processador. Revista Árvore, v.19, n.3, p. 346-57, 1995. 
SANTOS, S.L.M.; MACHADO, C.C.; LEITE, H.G. Análise técnico-economica da extração de eucalipto em áreas planas com o "forwarder". Revista Árvore, v.19, n.2, p. 213-227, 1995.

SEIXAS, F. Mecanização e exploração florestal: notas de aula. Piracicaba: ESALQ, LCF, 1998. 125 p.

SIQUEIRA, J.D.P. A atividade florestal como um dos instrumentos de desenvolvimento do Brasil. In: CONGRESSO FLORESTAL BRASILEIRO, 6., Campos do Jordão, 1990. Anais. Campos do Jordão: SBS, SBEF, 1990. p.15-18.

TIBURCIO, V.C.S.; SENE, J.M.; CONDI, L.G.B. Colheita mecanizada: Avaliação do harvester e forwarder. In: SIMPÓSIO BRASILEIRO SOBRE COLHEITA E TRANSPORTE FlORESTAL, 2., Campinas, 1995. Anais. Viçosa: SIF,UFV, 1995. p. 205-221.

VALVERDE， S.R.; MACHADO, C.C.; REZENDE， J.L.P.; SOUZA， A.P.; ANTIQUERA, A.C. Análise técnica e econômica do arraste com "skidder" no sistema de colheita de árvores inteiras de eucalipto. Revista Árvore, Viçosa, v.20, n.1, p. 101-109, 1996.

WADOUSKI, L.H. Fatores determinantes da produtividade e dos custos na colheita de madeira. In: SEMINÁRIO DE ATUALIZAÇÃO SOBRE SISTEMAS DE COLHEITA E TRANSPORTE FLORESTAL, 10., Curitiba, 1997. Anais. Curitiba: UFPr,FUPEF, 1997. p. 77-84. 